\title{
The Situativity of Knowing, Learning, and Research
}

James G. Greeno and the Middle School Mathematics Through Applications Project Group Institute for Research on Learning and Stanford University

The situative perspective shifts the focus of analysis from individual behavior and cognition to larger systems that include behaving cognitive agents interacting with each other and with other subsystems in the environment. The first section presents a version of the situative perspective that draws on studies of social interaction, philosophical situation theory, and ecological psychology. Framing assumptions and concepts are proposed for a synthesis of the situative and cognitive theoretical perspectives, and a further situative synthesis is suggested that would draw on dynamic-systems theory. The second section discusses relations between the situative, cognitive, and behaviorist theoretical perspectives and principles of educational practice. The third section discusses an approach to research and social practice called interactive research and design, which fits with the situative perspective and provides a productive, albeit syncretic, combination of theory-oriented and instrumental functions of research.

$\mathbf{T}$ his article is about a perspective on learning and cognition, the situative perspective, which has been discussed generally in several recent articles (e.g., Anderson, Reder, \& Simon, 1996, 1997; Clancey, 1997; Greeno, 1997; Lave \& Wenger, 1991; Norman, 1993; Rogoff \& Chavajay, 1995). We discuss this perspective broadly, in relation to other general psychological perspectives, the behaviorist and cognitive perspectives. We recognize that these broad perspectives can be viewed as complementary approaches (cf. Greeno, Collins, \& Resnick, 1996), and we agree that they are all valuable and needed. At the same time, we consider that the situative perspective can provide a synthesis that subsumes the cognitive and behaviorist perspectives, and we present this stronger contention.

In the first section, we discuss framing assumptions of a version of the situative perspective, and we argue for a way of conceptualizing the relation between situative analyses and analyses of individual cognition and behavior. We propose that the situative perspective provides functional analyses of intact activity systems ${ }^{1}$ and that cognitive and behaviorist analyses characterize mechanisms that support the achievement of these functions. We propose some generalizations of concepts in current cognitive analyses that we believe are favorable for accomplishing a coherent theoretical account of interactional and informational aspects of activity. We note that dynamic-systems analyses are providing generalizations of behaviorist concepts that contribute to this integration between levels of analysis, and we speculate that a situative synthesis that would analyze processes of communication and reasoning as trajectories of dynamic systems in state spaces of meaning and understanding could subsume both the cognitive and behaviorist perspectives. In the second section, we discuss educational practices from the point of view of the three perspectives, especially regarding principles of curriculum design and the organization of learning environments, and we argue that the situative perspective can provide a subsuming synthesis in this practical domain. In the third section, we discuss another kind of combination, that of basic and applied research. We discuss a style of research, variously called design experiments, pioneering research, and interactive research and design, which can bring together functions of theory-oriented and practice-oriented research in a partially integrated activity (i.e., in a syncretic combination).

\section{FRAMING ASSUMPTIONS OF THEORIES}

In our view, the main distinguishing characteristic of the situative perspective is its theoretical focus on interactive

Editor's note. Lyle E. Bourne, Jr., served as action editor for this article.

Author's note. Members of the Middle School Mathematics Through Applications group who contributed to this report include Shelley V. Goldman, Jennifer Knudsen, Raymond McDermott, Rick Berg, Beverly Bushéy, Karen Cole, Randi Engle, Lawrence Gallagher, Rogers Hall, Beatrice Lauman, Ralph Manuk, and Judit N. Moschkovich. We are grateful for comments by Eric Bredo, John Seely Brown, Robbie Case, Seth Chaiklin, Scott Noam Cook, Mariane Hedegaard, and Vera Mikalchik.

An earlier version of this article was presented by James G. Greeno as the recipient of the $1994 \mathrm{E}$. L. Thorndike Award from the Division of Educational Psychology, American Psychological Association.

This research was supported by the National Science Foundation, with Grants MDR9154119 and ESI9450522.

Correspondence concerning this article should be addressed to James G. Greeno, Institute for Research on Leaming, 66 Willow Place, Menlo Park, CA 94025 . Electronic mail may be sent via Internet to greeno@csli.stanford.edu.

${ }^{1}$ The term intact activity systems is analogous to intact organisms. The components of an intact activity system include individual cognitive agents, just as the components of an intact organism include the parts of its nervous system. We argue that functional analyses of intact activity systems are needed to frame the questions of research about individual cognition and behavior, so the results of that research can explain how those mechanisms support individuals' contributions to the functioning of the systems in which they interact. This is analogous to the familiar arguments that functional analyses of the behavior of intact organisms are needed to frame the questions of research about neural processes. 


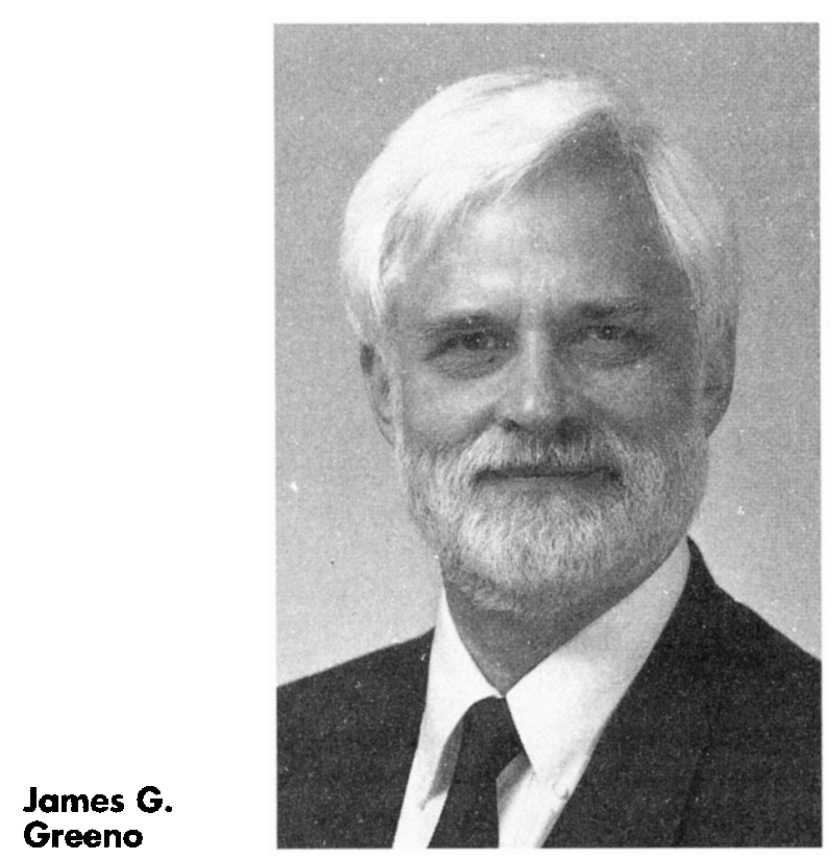

systems that are larger than the behavior and cognitive processes of an individual agent. This orientation has been advocated in the psychological literature for many years - for example, by Bartlett (1932), Bateson, (1972), Dewey (1896, 1929/1958), Kantor (1945), Lewin (1936, 1946), Mead (1934), Merleau-Ponty (1942/1962), and Vygotsky (1934/1987) - yet it has not prevailed. Instead, 20 th-century psychologists have focused theoretical attention on the behavior and cognitive processes of individual people and animals and have treated the rest of the social, material, and informational environments as contexts in which individual behavior occurs.

\section{Analyzing Information Structures in Socially Organized Activity}

During the past 40 years, research in cognitive science has achieved significant progress in developing concepts and methods of analyzing and representing structures of information involved in human activity. Psychology has played a key role in this interdisciplinary achievement, along with artificial intelligence (AI), linguistics, and the philosophy of mind and language. These studies focus on activities of individuals as they answer questions, solve problems, study texts, or respond to stimulus events. Most often, these activities are specified as experimental tasks or school assessments. The results include major empirical and theoretical advances in scientific understanding of perception, memory, language understanding, problem solving, and reasoning involved in individuals' performance of tasks (cf. Osherson \& Smith, 1990; Posner, 1989). Explanations are primarily in the form of models of processes of constructing, storing, retrieving, and modifying representations of information.
During this same time period there also have been strong scientific achievements in the study of social interaction, including concepts and methods of ethnography, ethnomethodology, discourse analysis, symbolic interactionism, and sociocultural psychology, which we refer to as interactional studies (cf. Star, 1996). This research focuses on interactive systems of activity in which individuals participate, usually to achieve objectives that are meaningful in relation to their more general identities and memberships in communities of practice. Paradigmatic situations in this research include people communicating with each other as they plan and evaluate their activities and coordinate their interactions with each other and with material and technological systems. Questions addressed in these analyses include how individuals and groups construct and interpret symbolic representations of information and ideas.

The main theoretical focus in these interactional studies is on principles of coordination in socially organized activity systems. Regular patterns of activity in a community, in which individuals participate, are characterized as practices of the community, and learning to become more effective in one's participation corresponds to becoming more central in a community's practices (Lave \& Wenger, 1991). Regularities of an individual's activities, in a trajectory that spans participation at different times in a community and participation in different communities, are characterized as the individual's identity (Wenger, in press), which is coconstituted by the individual's relation to communities and by the relation of those communities to the individual (Mead, 1934).

Although these lines of research - the study of individual cognition and of socially organized interactionboth provide important scientific knowledge and understanding, they have developed in relative isolation from each other. Cognitive science analyzes structures of the informational contents of activity, but has little to say about the mutual interactions that people have with each other and with the material and technological resources of their environments. Interactional studies analyze patterns of coordination of activity but have little to say about the informational contents of interaction that are involved in achieving task goals and functions.

We believe that this is a propitious time to explore ways of integrating these two lines of research. There are two obvious ways to proceed. One way is to begin in the framework of cognitive science and work outward from the analyses of individual cognition that have been developed. In this strategy, which has been spelled out and advocated by Vera and Simon (1993a), continued progress will occur incrementally by analyzing activity in increasingly complex situations. The other available strategy is to begin with the framework of interactional studies and work inward. In this strategy, progress will occur by focusing on the organization of intact activity systems and analyzing the informational contents of activity in which people accomplish the goals and functions of tasks that they undertake. 
Each of these strategies is reasonable, but also has drawbacks. The cognitive strategy starts by investigating properties of individual cognition, performing a kind of conceptual dissection into subsystems of cognitive processes. Experimental conditions are arranged to provide information about one of the processes of perception, comprehension, memory, inference, or judgment, assuming that the influence of other processes can be neglected in drawing conclusions about the process that the experiment is designed to investigate. It is hoped and expected that conclusions about these individual processes can be used to build up understanding of activity in which the various processes interact with each other when there are several individuals interacting with each other and with other systems, such as written representations or symbols displayed on a computer screen.

The cognitive strategy has important advantages, as Simon (1978) pointed out. If a complex system is made up of approximately decomposable subsystems, and we can learn the properties of those subsystems, we can develop an analysis of the complex system by building up theories from simpler to more complex units. The difficulty with this strategy, however, is also important. To investigate properties of cognitive subsystems, some general activity structures have to be arranged in which those subsystems function. Because we have not yet understood the relations between subsystems, we depend on a factoring assumption-that the properties of the subsystem we are investigating do not depend significantly on the ways in which the other subsystems behave in the specific conditions that we have chosen. Without analyzing the larger systems thoroughly, we risk arriving at conclusions that depend on specific features of activities that occur in the special circumstances that we arrange, and that these specific features will prevent generalization to the domains of activity that we hope to understand.

The situative strategy starts by investigating activity in intact multiperson, human-technology systems, asking how such systems function. This leads to conclusions about principles of coordination of interactive systems. With these conclusions, situative research can investigate the properties of individual's cognition and behavior that support their contributions to the functioning of the systems in which they participate. The drawback of this strategy is that we are required to examine complex systems without yet having a thorough understanding of their component subsystems. On the other hand, we can hope to understand functionality of the larger systems, and then use conclusions of these functional analyses to guide analyses of the subsystems.

We believe that the field should pursue both of these strategies vigorously, and that investigators of both persuasions should keep track of progress being made along both lines. The strategy that we are pursuing is the situative alternative, and the rest of this section presents an account of some reasons for proceeding in this way, and some general proposals for it.

\section{Some Characteristics of Activity That Seem Problematic for Cognitive Analysis}

Any theoretical perspective makes some phenomena relatively easy to account for and makes other phenomena more problematic. We mention three aspects of problem solving, communication, and participation in activity that seem more simply accounted for by concepts that are focused primarily at the level of interactive systems rather than individual agents.

Emergent problem spaces. A key concept in cognitive analyses is the problem space, which represents the understanding of a problem by a problem solver, including a representation of the situation, the main goal, operators for changing situations, and strategies, plans, and knowledge of general properties and relations in the domain. In the standard cognitive analysis, for which Newell and Simon (1972) provided prototypes, problem solving is conceptualized as a search in the problem space or as applications of known methods for moving through the space to the goal.

A cognitive analysis is most straightforward when the problem space is well-defined and stable, but in many situations significant aspects of the problem space emerge in the process of working on the problem. We illustrate this with three examples. First, the emergent character of problem problem spaces was recognized early by Reitman (1965) in a study of composing a fugue. As is generally the case in problems of design and composition, Reitman found that the composer constructed a problem space throughout the process of problem solving as he made decisions that imposed constraints on further work. A second example is discussion given by Lave (1988), who studied people buying groceries and showed that the goals and shapes of solutions of problems were coconstituted by the shoppers' general intentions and expectations and by the physical layout of products and resources for inferring relative values of alternative purchases. A third discussion was given by Suchman and Trigg (1993), who studied a pair of AI researchers working on a problem of designing some components of a program and showed that problem goals and subproblems emerged in the interaction between the participants in the activity.

When significant features of the problem space emerge in activity, a theory needs to include processes that construct and modify the problem space. In the cognitive literature, changes in the problem space have been analyzed as ill-structured problems, for example, by Simon (1973), and the information-processing framework is being used in analyses of increasingly complex problem domains (Vera \& Simon, 1993a). These analyses assume that problem solvers have processes that construct new operators or combine operators and subgoals from multiple problem spaces. Including these processes makes the analysis considerably more complicated, and although analyses of ill-structured problem solving can be developed in the standard cognitive framework, prob- 
lem solving with emergent problem spaces presents a relatively difficult challenge in the cognitive framework.

Inferactive construction of understanding. Standard cognitive analyses of understanding have been worked out mainly for comprehension of written texts. Models of text comprehension include hypotheses about processes of recognizing patterns as words, parsing sequences of words to form representations of propositions, and constructing coherent networks of propositions (e.g., Just \& Carpenter, 1980). Construction of these coherent networks depends on general strategies, such as linking propositions that have the same argument, and on retrieving and applying knowledge structures, such as causal relations and other schemata, in the domain (e.g., Kintsch \& van Dijk, 1978).

Similar to solving problems with stable problem spaces, the activity of reading a text occurs in a stable environment. Many situations in which people construct understanding are dynamic, in much the same way as problems with emergent goals, operators, and criteria of solutions. One aspect of this dynamic character involves one of the simplest functions of symbols-to refer to some object, person, or place. Schegloff (1972) and Clark and Wilkes-Gibbs (1986), in analyses of the interaction between participants in conversations, have shown how reference is an achievement of joint action, rather than being a property of a symbol itself. The meanings of symbols are often interpreted in relation to problems that emerge in ongoing activity (Goodwin \& Goodwin, 1996). Standard cognitive analyses of these phenomena are possible, of course, by hypothesizing schemata and procedures for constructing representations of meaning that are contingent on contexts. Again, this makes the analysis more complicated, especially when the relevant "context" is constructed dynamically in ongoing conversations and in problematic aspects of activity.

Engagement in acfivities, including contributions to group functions and individual identity. Analyses of motivation and affect that have been developed in the cognitive perspective have focused on characteristics of individuals. In analyses of problem solving, motivational issues are addressed by hypotheses about how individuals set goals. Lack of motivation would correspond to lack of a procedure that sets a goal to solve the problem, or to not activating such a procedure. There also have been important investigations of intrinsic motivation (Lepper \& Greene, 1979) and differences between individuals in their beliefs about themselves as knowers and learners. These differences in beliefs go with very significant differences in ways that people consider their own knowledge and in their engagement and participation in activities that present challenges and in which they engage in construction of knowledge (Belenky, Clinchy, Goldberger, \& Tarule, 1986; L. M. Brown \& Gilligan, 1992; Dweck \& Leggett, 1988).

Engagement in activities also depends on the interactions of individuals with other people. For example, Eckert $(1989,1990)$ analyzed students' affiliations with communitics of practices that are common in American high schools, called "jocks" and "burnouts" in the school she studied. Eckert found that students' participation in activities and classes was very strongly influenced by these affiliations. Jocks and burnouts had very different general orientations toward their school as an institution, and the students' positive or negative participation in activities and classes functioned in important ways to express and maintain their affiliations in communities. Belenky, Bond, and Weinstock (1997) developed and studied activities in which women were supported in their participation in reflective problem solving and planning about themselves, and reported substantial changes in these women becoming more active and confident in their thinking and in their claims to understanding and knowing.

\section{Generalizations of Concepts of Procedures, Schemata, and Meanings}

In our efforts to develop analyses of processes such as problem solving, understanding, and engagement in intact activity systems, we consider questions about information structures for which cognitive science has developed powerful theoretical concepts and analytical methods. We have not found that the concepts and methods of standard cognitive science are adequate in the form that they have been developed, but we have developed generalized versions of these concepts and methods that are promising. This section presents these generalizations.

Attunements to constraints and affordances. In the cognitive perspective, explanations are in the form of models that simulate aspects of activities such as solving problems, reading and understanding texts, recognizing patterns, making decisions, and so on. These models are constructed with hypotheses about two main kinds of structures: schemata and procedures. The explanations are hypotheses about representations that are perceived, remembered, and constructed according to schematic patterns, and about procedures that receive, retrieve, transform, and store those representations.

A concept of attunements to constraints and affordances provides an alternative, more general form of explanation of activity. For example, Reitman (1965) did not provide an explanation of his composer in terms of procedures and stored schematic patterns, but he discussed the activity of composing a fugue in terms of constraints that the composer considered, including properties of the piece that satisfied constraints of the fugal form, properties of melody and phrasing that he judged appropriate for a piano, the instrument he was composing for, and properties of the music that satisfied stylistic criteria that the composer felt were important. At the same time, the fugal form, the acoustical properties of pianos, and stylistic genres also provided affordances for the composer in supporting his construction of musical patterns and passages with properties that he valued.

Lave (1988) also did not provide procedural explanations of grocery shoppers' solving problems about prices of products as they shopped. Instead, she charac- 
terized problem solving as responses to "snags" that emerged in shopping. In their reasoning about prices, shoppers used regularities of numerical patterns of the kind that mathernatics educators call "number sense," rather than standard numerical calculations. These regularities are a form of constraints and affordances in the domain of numerical reasoning. Lave also discussed shoppers' activity in terms of other constraints they were attuned to, such as needing enough fruit for snacks during a week when children would be home from school, not buying a larger quantity than they could accommodate in their kitchen storage, and preferring to purchase a product with minimal unit price. She also discussed properties of the supermarket that provided affordances, including the physical layout of the store, the proximity of similar products, and the numerical symbols that provided information about prices.

Suchman and Trigg (1993) discussed ways in which the activity of designing an AI program used, and was accountable to, resources and practices in their professional research community, as well as their personal experience in the domain of personal-time scheduling, which their AI program was designed to assist in. They developed their understanding of problems, proposals for solutions, and evaluations of proposed solutions in collaborative interaction. The researchers engaged in a common form of constraint-based reasoning, posing possible program structures and inferring what the behavior of their program would be like if they included those structures. Suchman and Trigg attended especially to representations that the researchers constructed on a white board that provided affordances for their attending to constraints and defining subproblems in their design problem.

The concepts of constraints and affordances have been developed explicitly in situation theory and ecological psychology. In situation theory (Barwise, 1993; Barwise \& Perry, 1983; Devlin, 1991), constraints are represented formally as if-then relations between types of situations. We use the term constraints to include if-then regularities of social practices and of interactions with material and informational systems that enable a person to anticipate outcomes and to participate in trajectories of interaction. Affordances (E. J. Gibson, 1988; J. J. Gibson, 1979/1986; Reed, 1996) are qualities of systems that can support interactions and therefore present possible interactions for an individual to participate in. Affordances can be represented, using situation-theory notation, as if-then relations between types of situations, in which the antecedent involves resources in the environment and enabling characteristics of a person or group and the consequent is a type of activity that is possible whenever those environmental and personal properties are present. Regular patterns of an individual's participation can be conceptualized as that person's attunements to constraints (Barwise \& Perry, 1983) and to affordances. Attunements include well-coordinated patterns of participating in social practices, including the conversational and other interactional conventions of communities. At- tunements also include patterns of action involved in using artifacts that provide resources for practices.

The concept of attunements to constraints and affordances is more general than the concepts of schemata and procedures. Schemata are representations of regularities that enable information and actions to be organized according to patterns. The same regularities can be represented as constraints, involving co-occurrences of properties and relations in types of situations. Procedures are special cases of constraints. Each component of a procedure involves a kind of action that is executed when the situation matches a condition represented as a pattern of information. The condition-action pair is a constraint, and the condition designates an affordance for performing the action. Systems of attunements to constraints and affordances, then, can include all of the elements of a schema-procedure system, but they can include other elements as well, as the examples from discussions by Reitman (1965), Lave (1988), and Suchman and Trigg (1993) have illustrated.

We emphasize that attunements to affordances and constraints of activity systems support individuals' participation in activity systems but do not determine them. Activity is a continual negotiation of people with each other and with the resources of their environments. There are regularities of practice that hold up across situations, and attunements to those regularities can make people more successful, but these attunements significantly underdetermine important aspects of what people do.

Relational theory of meaning. In standard cognitive analyses, meanings (e.g., of texts) are represented as structures of information that connect concepts with each other in a network of propositions. Situative analyses emphasize communication and reasoning about objects in the settings of activity. To represent such referential meanings, we propose use of another concept from situation theory, where referential meanings are characterized as relations between situations, rather than as properties of symbolic expressions. In a conversational interaction, the meaning of an utterance is considered, not as a property of the utterance itself, but rather as a relation, called a refers-to relation, between the situation in which someone makes the utterance and a situation to which the utterance is interpreted as referring (Barwise \& Perry, 1983).

Using this idea, we can construct representations of meanings that we infer to be constructed by participants in conversations. Researchers in conversation analysis (e.g., Schegloff, 1991) and psycholinguistics (e.g., Clark, 1996; Clark \& Schaefer, 1989) have analyzed ways in which participants in a conversation mutually construct meanings in a process that includes presentations; responses of accepting, questioning, or objecting; and affirming or repairing interpretations to reach mutual understanding. We identify meanings as relations between these joint actions of achieving mutual understanding and the states of affairs, types of situations, or ideas that the participants interpret their statements as referring to. A 
basic part of the interpretive process is constructing the referential meanings of terms, which Schegloff (1972) and Clark and Wilkes-Gibbs (1986) analyzed as collaborative achievements by the participants in conversations.

We also extend Barwise and Perry's (1983) relational idea of meaning to apply to the various kinds of actions and objects that people interpret as having referential meaning, including written or drawn symbols, iconic gestures or diagrams, and spoken, gestured, written, or drawn indexes (Peirce, 1897-1910/1955). Signifiers, which include symbols, icons, and indexes, have meanings when people interpret them, thereby constructing refers-to relations between occurrences of the signifiers and entities that they designate. Conventions of interpreting meanings of symbols, icons, and indexes are a crucial part of social practices, and attunements to those constraints and affordances of interpretation are a crucial part of individuals' participation in those practices. Patterns of turn-taking and other conventions of participating in conversation can be considered as attunements to conventions of discourse practices. As with other aspects of activity, the sequences of communicative and expressive actions and meanings that occur in any specific situation are underdetermined by the constraints and affordances of social practice, so that significant aspects of meaning are generated in the situations where people are communicating, reasoning, and making sense. These interpretations are integral components of the ongoing activities that people are engaged in as they solve the problems that emerge (e.g., Goodwin \& Goodwin, 1996).

Engaged participation: Contributions and identity. To begin to reach some of the issues of engagement in and disengagement from activities, we generalize the ideas of procedures for setting goals, intrinsic interests, and attribution processes to broader concepts of attunement to constraints and affordances of social practices and identity. Constraints and affordances of social practices also constitute the criteria by which solutions of problems are judged to be superior, acceptable, or deficient.

Strategic knowledge in cognitive models simulates problem solvers' adoption of tasks and their knowing how to organize their activity so they progress toward successful solutions of problems. This strategic knowledge has the form of procedures that set goals and evaluate progress according to criteria of problem-solving domains. An individual who adopts challenging tasks in a domain is often characterized as having a strong intrinsic interest in that domain. The situative perspective conceptualizes these aspects of knowing and motivation in terms of participation in social practices. Communities of practitioners share standards of what characterizes worthwhile problems to engage in and what constitutes an adequate or excellent solution of such a problem. These standards can be understood as constraints and affordances of practices - characteristics of problems that make them valuable to work on and characteristics of solutions that are required or particularly valued.
It should not be assumed that the situative perspective somehow implies that all members of a community conform to a single set of standards and values in their activity. People participate in communities in many different ways - some by adopting the mainstream standards and values, some by rejecting them, and most by a mixture of conformity to and alienation from different aspects of the prevailing standards and values. Many communities value significant forms of nonconformity and recognize individuals' unusual contributions as having special merit. In any case, individuals develop identities in which they relate to the prevailing standards in a complex variety of ways.

In the situative perspective, engagement in general aspects of activities associated with institutions, such as having a commitment to succeeding in schoolwork (Eckert, 1989, 1990), and having a positive orientation toward activities of learning and construction of knowledge (Belenky et al., 1997), involves issues of affiliation and identity in communities of practice. In schools - especially high schools - students' affiliations in formally organized groups such as gangs, as well as in informal networks, are crucial in the development of their identities, and these groups can form their identities in ways that oppose the school's preferred participation structures, as well as in ways that facilitate the students' engagement in academic and extracurricular pursuits that are valued positively by the institution. More broadly, individuals' beliefs and patterns of participation in activities of learning are shaped by their interactions in families as well as in schools and other organizational settings, where they and others develop expectations of participating authoritatively or in subservient relations to others on matters of knowledge and intellect.

\section{Some Criteria of a Theoretical Synthesis}

The accomplishments of the cognitive research program have established high standards for scientific explanation of informational content in activity. For an alternative to succeed, it should aspire to meeting those standards, which include the following criteria.

1. It must provide empirical hypotheses about structures of information that are generated and used in activity and about ways in which that information functions in activity.

2. It must include theoretical concepts that characterize processes and general patterns that provide explanatory accounts of the information structures that are generated by people in activity.

3. The concepts that explain information structures in performance must have the potential to be developed into explanatory accounts of learning, transfer, and motivation.

4. It is desirable to formulate situative models that are specific enough to implement them as simulation programs, thereby demonstrating that the hypotheses are computationally sufficient to explain phenomena that are simulated.

Considerable progress needs to be made in order to demonstrate the adequacy of the situative framework to meet these criteria. However, we believe that the concepts 
that we have sketched here have the potential for supporting such a development.

Representations of information constructed in activity. Representations of information in the framework we have sketched can be developed in detail, much as they are in the familiar framework of information processing. The representations that we construct extend the scope of typical semantic-network representations to include the refers-to relations of situation theory; we have coined the term semiotic networks to refer to these expanded representations (Greeno \& Engle, 1995).

Our interpretation of these theoretical representations involves a distinction that is not made in the standard information-processing framework. In the standard framework, hypotheses about cognition involve mental representations, all of which designate external states of affairs (Vera \& Simon, 1993b). We distinguish between representations that are interpreted by people as referring to states of affairs or concepts and mental states of affairs that are causally involved in behavior but are not interpreted by agents as having referential meaning (Greeno \& Moore, 1993). Semiotic networks represent symbols and other signifiers that people interpret with referential meaning. Mental states and processes that are hypothesized in an explanation of people's information processing can also be considered as representations, but they have a different status. We follow Hatfield (1991) in considering these states as representational when they figure in a functional account of activity that attributes informational functions to those states and processes. We assume that most of the refers-to relations that we represent in semiotic networks are functional, in this sense, rather than having interpreted representations in participants' mental structures. That is, we do not generally assume that refers-to relations have interpreted representations unless there is evidence of an explicit representation of a referential relation, for example, by someone saying something like "This means such-and-so." In a situative theory, analyses of mental representations that do refer include hypotheses about what they refer to in activity, rather than merely what their properties are and how they are modified by symbol-manipulating procedures.

Schemata and concepts as athunements to constroints and affordances. In their participation in processes that construct information, including representations and their meanings, participants are attuned to constraints and affordances of social practices, including representational systems as well as the systems whose behaviors are represented. We use a concept of schemata to refer to collections of attunements to interrelated constraints and affordances. Schemata include attunements to constraints and affordances of activity with physical systems, for example, operating material systems in activities such as driving cars or cooking. Schemata also include conventions of social practice, such as patterns of turn-taking in conversation, appropriate ways to interact conversationally when working together on a task, and what kinds of products are expected in order to decide that a kind of task has been accomplished. Conventions of social practice also include ways to use symbols and other signifying actions and objects in spoken communication, in constructing material representations, and in interacting with informational technologies such as books and computer systems.

Participating in a community includes understanding the concepts that are significant in the community's discourse about its activities. Some of this discourse is explicitly about meanings of concepts. Much successful practice, however, depends on implicit understanding of concepts - involving attunements to constraints and affordances that constitute the meanings of concepts for which the person may not know the explicit representations that are used by other people to discuss the concepts' meanings (Greeno, 1995).

As with representations of information, we do not assume that the representations we construct of schemata and meanings of concepts necessarily correspond to representations that people construct in their cognitive processes. Of course, people can, and often do, construct representations of concepts and of general patterns of ideas and activities. The processes of constructing and interpreting such representations are crucially important in social practice and are a fundamentally important topic of scientific inquiry (e.g., Hall, 1996).

Learning, transfer, and motivation. Learning, in this situative view, is hypothesized to be becoming attuned to constraints and affordances of activity and becoming more centrally involved in the practices of a community (Lave \& Wenger, 1991), and transfer is hypothesized to depend on attunement to constraints and affordances that are invariant or modifiable across transformations of a situation where learning occurred to another situation in which that learning can have an effect (Greeno, Smith, \& Moore, 1993). Regarding motivational issues, the situative perspective emphasizes ways that social practices are organized to encourage and support engaged participation by members of communities and that are understood by individuals to support the continuing development of their personal identities.

Computational formalisms. The use of computational formalisms as a theoretical medium can be adapted to the kind of situative analyses that we are advocating. A programming language can be used as a calculus for expressing descriptions of information structures that are involved in cognitive processes, according to hypotheses framed by situative assumptions. In the program, these descriptions can be generated from representations of constraints and affordances that correspond to attunements that are hypothesized. Such representations are hypotheses about properties of information, but the theoretical representations need not be interpreted as corresponding to symbolic representations that agents construct and interpret. Theorists' representations are important for expressing their hypotheses explicitly and applying rules of deductive inference to derive implications of assumptions, but expressing a hypothesis about information with symbols in a theory need not imply that 
the people engaged in an activity construct interpreted symbolic representations as part of their activity.

\section{An Example}

To make these general ideas more concrete, we sketch an example of an analysis that uses some of these concepts. The episode that we discuss was most of a threeminute conversation between a middle school teacher and a student about a draft report that the student had written. The class was working on a project in a curriculum called Antarctica, which uses an interactive computer program called ArchiTech that supports students' work in designing buildings. (We discuss this curriculum more generally as an example of educational practice in the section entitled Participation in projects that use mathematics, beginning on p. 20.) Groups of four to five students were working on designs of living and working space for a hypothetical group of four scientists who would be in Antarctica for two years. ArchiTech includes a graphics interface with which students construct floor plans and specify quantitative parameters such as the quality of insulation and assumptions about average outdoor and indoor temperatures. Students can use the program to calculate values of quantities such as the estimated construction cost of a building they have designed and the projected monthly cost of heating the building with their assumed values of temperatures and insulation quality. Most of their attention is given to allocations of space for the various functional requirements of work, sleeping, recreation, and so on, and meeting requirements of cost and total space.

The episode that we discuss involved a special assignment that the teacher gave to find the value of insulation quality, called " $R$ value," that would minimize the total cost of construction and heating for two years. For this analysis, the students conducted computational experiments, keeping their designs and assumptions about temperature constant, and using the program to calculate, for each of several $R$ values, construction and monthly heating costs, which they converted to the cost for two years.

In the teacher's and student's conversation, the student explained her group's analysis, which they based on a table of values that associated a construction cost and a two-year heating cost with each of several $R$ values. They focused on pairs of successive values, noting how much construction cost was increased, and how much heating cost was decreased, for each increment of $R$ value. They chose the value $R=20$ because between $R$ $=10$ and $\mathrm{R}=20$, the increase in construction cost was less than the decrease in heating cost, but between $\mathrm{R}=$ 20 and $R=30$, the increase in construction cost was greater than the decrease in heating cost. The teacher had expected a different form of analysis, in which total costs (construction plus heating) would be calculated for each $R$ value, choosing the $R$ value that minimized total cost. In the conversation, we infer that the teacher and student successfully constructed a shared understanding of the students' analysis and why it was correct.
The kind of situative analysis that we carry out for an episode such as this has several components. One focuses on the interpersonal interaction of the conversation, involving turn-taking, conversational openings, responses, and contributions (Clark \& Schaefer, 1989; Sacks, Schegloff, \& Jefferson, 1974). It was important in this conversation that the participation structure provided opportunities for the student to explain the group's method, rather than a pattern in which the teacher evaluated their analysis as being incorrect because it did not correspond to the form that she was expecting.

We also focus on structures of information in the contents of the conversation. These include refers-to relations of the numerical symbols in the table that the students had constructed. Our analysis of these semantics includes reference of symbols to different versions of the design, each of which is an entity in a conceptual domain that the class had established in its discourse. Each of these design versions had the numerical properties of $R$ value, construction cost, and heating cost that were represented in a row of the student's table, and the meanings of these symbols are included in our theoretical representation of the information structures that the teacher and student generated.

The students used the symbolic representations in their tables in reasoning to solve the problem of selecting the optimal $\mathrm{R}$ value, and the student and teacher constructed a mutual understanding of this reasoning in their conversation. This involved attention to the pairs of successive values in the table, calculating the differences, and comparing the sizes of differences in the two columns to infer that beyond $R=20$, further increases in $R$ caused greater increases in construction than decreases in heating. These inferences are also included in our theoretical representation of the information that the teacher and student generated, as well as the relation of these inferences as support for the conclusion that $R=20$ was optimal.

To account for the various aspects of this conversation, we hypothesize that the teacher and student were attuned to several constraints and affordances, which we consider as schemata. They were attuned to constraints and affordances of conversational interaction, which supported their turn-taking, including the expectation that the student would have opportunities to explain the design group's reasoning. They were attuned to constraints and affordances of constructing and interpreting symbolic representations in numerical tables. They were attuned to regularities in the domain of building design, including the constraint that higher values of insulation cause increased construction costs and decreased heating costs. They were also attuned to constraints and affordances of arithmetic operations, which they used in calculating and comparing differences.

The teacher was apparently not attuned initially to the constraints and affordances involved in choosing an optimal $R$ value using the sizes of incremental differences in the two cost components, although she followed the student's explanation and affirmed her understanding of 
the method. The conversation, therefore, includes evidence that learning may have occurred, as the teacher may have become attuned to constraints and affordances of reasoning that she was not attuned to at the beginning. To make a strong case for learning, we would need to have evidence in later behavior that the teacher acted on the basis of these attunements.

We have not constructed a computational model of this interaction, but for illustrative purposes, we mention the way that we would develop such a model. Using a programming language designed to compute implications of constraints, we would develop representations of constraints that we have discussed informally in these paragraphs. The model would provide an account of the conversation to the extent that implications of the hypothetical constraints would match information structures that were generated by the participants, inferred from evidence in their conversational interaction.

\section{Analyzing Behavior Patterns as Dynamic- Systems Aftractors}

The shift that we call situative - from focusing on behavior of individuals to focusing on behavior of systems in which individuals participate - is also a characteristic of analyses in ecological psychology in terms of dynamic systems. These analyses characterize behaviors of systems, which include individual agents, as continuous interactions through time, represented as trajectories through a state space (e.g., Thelen \& Smith, 1994). A complex dynamic system can be characterized in terms of component dynamic systems that interact through a coupling that coordinates their trajectories.

A key concept in dynamic-systems analyses is that of attractors, which are trajectories through state spaces that represent regular patterns of interactive activity, extended in time, of systems that include behaving agents acting in environments. Learning is characterized as the development of attractors that have increasingly integrated components and that support increasingly successful interaction with systems in the environment.

The change from traditional behaviorist theory to dynamic-systems theory is, quite literally, a Newtonian shift. Before Newton, the explanatory system of mechanics treated each occurrence of motion as something to be explained. Newton, who formulated mathematical dynamics (Abraham \& Shaw, 1992), postulated in his first law that an object in motion tends to remain in motion, so that changes in motion became the phenomena to be explained. Behaviorism is analogous to pre-Newtonian physics, in that each occurrence of behavior is taken as something to be explained, as a response to some stimulus by a motivated organism. In psychological dynamicsystems theory, activity is characterized in terms of trajectories of action-environment interactions, which tend to be maintained unless something happens to change them. Sometimes activity can be described approximately as a response to a stimulus, of course. Such events are a special cases of a dynamic system when a stimulus event changes the environment in such a way that a distinctive trajectory captures the individual's activity.

\section{A Possible Situative Synthesis}

We find it promising to consider a potential synthesis of dynamic-systems analyses and analyses of symbolic communication and reasoning that are based on the idea of practices, where practices are considered as schemata involving attunements to families of interrelated constraints and affordances. The development that we envision could merge behaviorism's emphasis on activity in environments with cognitivity's emphasis on the informational contents of activity, including the role of symbols and meaning. This would involve analyzing processes of communication and reasoning as trajectories of dynamic systems in state spaces of meaning and understanding. Attractors would correspond to patterns of social practice in inquiry, explanation, and argumentation. This would involve a Newtonian shift in the analysis of cognitive processes analogous to the shift from stimulusresponse behaviorism to the dynamic-systems analysis in ecological psychology that we discussed previously.

In this view, schemata of practices would be considered as attractors in the theoretical state space of interactions that people have with each other and with material, representational, and conceptual systems in their physical and social environments. Some preliminary analyses that focus on patterns of interpersonal interaction have been developed (Vallacher \& Nowak, 1994). Schemata of a practice also include trajectories of performing to accomplish various kinds of tasks, as well as trajectories of participating in discourse, such as patterns of turn-taking, that take into account the participants' various positions of status in the social arrangement that prevails.

Schemata involving informational contents of discourse include trajectories of activities that construct representations according to general forms that are used in the practice. These include the syntax of language that the participants share, as well as other forms of representation such as numerical symbols, diagrams that are used in standard ways, and gestures that represent properties of events being described. Schemata of discourse also include trajectories of referential meanings that the signifiers used in discourse are about. These include trajectories of representations of events that have a sequential, causal, or motivational structure, and trajectories of explanations that relate representations of some phenomena to representations of general principles that are offered as a way of understanding the phenomena.

\section{Cognitive and Behoviorist Analyses of Mechanisms of Interactive Activity}

We have presented a preliminary set of concepts that we believe are promising as a framework for combining interactional and informational analyses of activity. Analyses in terms of these concepts focus primarily on properties of intact activity systems, especially on principles of coordination between the various components of such 
systems. These components include the several individual people who are interacting, when there is more than one human participant, and the various resources they use in their activity, including material as well as informational systems.

In this conceptual framework, analyses of individual cognition and behavior can provide mechanistic explanations, showing how the functions of interactive activity systems are accomplished. The pattern of explanations that are functional at one level and mechanistic at a more molecular level is common in science, and in ordinary reasoning as well (e.g., Miyaki, 1986).

We expect that functional analyses of intact activity systems will guide the development of analyses of individual behavior and cognition that will be more general than those that have been developed up to now. We anticipate that analyses that we have now will provide important special cases that are valid when the conditions of activity approximately satisfy the factoring assumption of approximate decomposability. The analyses of cognition and behavior that we have now assume that the various aspects of activity in a system can be factored so that some processes can be explained by each individual's knowledge or stimulus-response associations, and the rest can be explained by effects of the context. This factoring assumption provides a reasonable approximation for the analysis of some aspects of activity in some situations. Examples in which the cognitive assumption succeeds include analyzing the information that an individual constructs in reading a printed text or analyzing the steps in constructing a solution to a problem with a stable problem space such as Towers of Hanoi or high school geometry. Examples in which the behaviorist assumption succeeds include stable conditions of reinforcement contingent on discrete responses or consistent pairings of verbal items that are counted as correct. However, the cognitive and behaviorist perspectives assume that this factorability is a general property of activity systems, and this assumption is questionable, at best. The situative perspective offers a more general framing, in which significant aspects of activity evolve in processes of coconstruction and negotiation between participants and other systems in situations. The kind of factoring assumed in cognitivity and behaviorism can hold, approximately, as a special kind of interaction, but we need more general concepts to understand the kinds of interaction that occur in many kinds of situations between an individual and other people and between people and other systems. We believe it will be productive to investigate processes of individual cognition and behavior in relation to more general patterns of interaction, and that this line of inquiry will support progress toward an integrative scientific understanding of activity.

\section{PRINCIPLES OF EDUCATIONAL PRACTICES}

The relation between theoretical perspectives and educational practices involves design principles that A. L. Brown (1994) has called first principles, and J. S. Brown (1991) has called tacit assumptions of practice. Different assumptions about the processes and goals of education underlie different ways of organizing educational activities. Schools that are organized according to the different models have different learning practices, and they assess students by different criteria. Students learn not only what they are taught explicitly, but also develop patterns of participation and identities that are shaped by these different practices in which they learn. Behaviorist principles tend to characterize learning in terms of acquisition of skill. Cognitive principles tend to characterize learning in terms of growth of conceptual understanding and general strategies of thinking and understanding. Situative principles tend to characterize learning in terms of more effective participation in practices of inquiry and discourse that include constructing meanings of concepts and uses of skills. We argue here that the situative perspective, focused on practices, can subsume the cognitive and behaviorist perspectives by including both conceptual understanding and skill acquisition as valuable aspects of students' participation and their identities as learners and knowers.

\section{The Situative Perspective}

Viewed in the situative perspective, all arrangements of activity provide situations and practices in which learning occurs, and all learning occurs in some situation. The difference between learning in different arrangements is not whether learning is situated or not, but how it is situated. The situative perspective emphasizes aspects of problem spaces that emerge in activity, the interactive construction of understanding, and people's engagement in activities, including their contributions to group functions and their development of individual identities. The perspective focuses on the activities and practices of learning and includes participation in these practices as part of what students learn. Because students learn how to participate in the practices of learning (positively or negatively), it is important to attend to the kinds of participation in learning and knowing that are afforded and valued in schools and other learning environments. Thus, taking the situative perspective, learning environments organized on behaviorist skill-acquisition principles encourage students to become adept at practices, involving receptive learning and drill, that result in efficient performance on tests, and learning environments organized on cognitive knowledge-structure principles encourage students to become adept at constructing understanding on the basis of general ideas and relations between concepts.

As a scientific perspective, situativity does not say what educational practices should be adopted. However, it does say that the activities of different learning practices are important, not only for differences in their effectiveness or efficiency, but also because participation in those practices is fundamental in what students learn. If we value students' learning to participate in practices of inquiry and sense-making, we need to arrange learning practices of inquiry and sense-making for them to participate in. This kind of practice has been advocated by Dewey (e.g., 1910/1978), and is a major focus of many 
current reform efforts (e.g., National Council of Teachers of Mathematics [NCTM], 1989).

The activity systems of education that are oriented to these practices encourage students to participate in processes that include conceptual inquiry and use of skills in solving problems that emerge in meaningful projects. Their intent is to extend students' learning activities to include formulation and evaluation of conjectures, examples, applications, hypotheses, evidence, conclusions, and arguments, and to have conceptual growth and skill acquisition occur in relation to these participatory activities. In these participation-oriented educational practices, class discussions are organized not only to foster students' learning the content of what is discussed, but also their learning to participate in the discourse practices that organize the discussions. Groups of students work on projects, not only to learn about the topics that the projects are concerned with and the skills that are required to accomplish the projects, but also to develop abilities of collaborative inquiry and of using the concepts and methods of a discipline to solve problems that arise in diverse activities. Forms of representation are used, not only to express information and concepts in a subjectmatter domain, but also to enable students to learn to use and appreciate those representational systems in developing and sharing their understandings of questions, hypotheses, and arguments in the domain. By learning to participate in activities involving inquiry and substantial projects, students can progress in their development of identities as active, critical learners, in their own selfconcepts and the understanding that others have of them.

There are two general approaches that share the main organizing principle of providing students with opportunities to participate in practices of inquiry. These two approaches, which can be combined productively, involve students' reasoning in the target subject-matter domains and reasoning with the concepts and methods of the target subject-matter domains. In the first approach, which is more frequent, school activities are organized as inquiries in the concepts and methods of subject-matter disciplines. Applications are used mainly to illustrate the concepts and methods of the subject-matter disciplines. In the other approach, school activities are organized mainly around projects in domains other than the target subject-matter, in which students use concepts and methods of the target subject-matter disciplines to accomplish other achievements. In this second approach, students learn the subject-matter concepts and methods primarily as useful resources and participate in inquiry into the relative use of alternative concepts and methods. Discussions that focus explicitly on meanings and structures of subject-matter concepts and methods are grounded in the experience of students in their projects.

In a classic example of the first approach, Fawcett (1938) organized a high school geometry course so students could learn to participate in processes of deductive reasoning. Fawcett's main goals were for students to learn practices of formulating explicit definitions and postulates and of evaluating whether conclusions follow as deductive consequences of stated definitions and premises. In the mathematical material of the course, each student constructed her or his own mathematical development of geometry, choosing from alternative ways to define concepts and postulates, stating and proving theorems, and presenting examples. Throughout the course, examples of conclusions presented in advertisements and news stories about public affairs were discussed in class, and students became adept at constructing the kinds of definitions and assumptions that would be required to reach those conclusions by rigorous arguments.

In several current research-and-development projects, students' activities are organized around inquiry in subject-matter disciplines. Some of these projects are in mathematics, in which students at various levels participate in developing definitions, conjectures, representations, and arguments (Ball, 1993; Cobb et al., 1991; Healy, 1993; Lampert, 1990b; Moses, Kamii, Swap, \& Howard, 1989; Schoenfeld, 1994). Other projects develop and study activity systems in which students participate in developing and evaluating hypotheses and arguments in science (A. L. Brown \& Campione, 1994; Goldman, 1996; Hatano \& Inagaki, 1991; Reiner, Pea, \& Shulman, 1995; W.-M. Roth \& Bowen, 1993-1994) and social studies (Collins, Hawkins, \& Carver, 1991; Scardamalia, Bereiter, \& Lamon, 1994).

There also are current projects that use the second approach; that is, they develop and study learning environments in which students use concepts and methods of a discipline, such as mathematics, in projects that are mainly in another domain (Cognition and Technology Group at Vanderbilt, 1994; Goldman, Maschkovich, \& the Middle School Mathematics Through Applications Project [MMAP] Team, 1995). In these learning environments, activities are organized in which subject-matter concepts and methods are implicit in the design activities. These activities also provide motivation for developing explicit discussions of conceptual meanings and abstract representational forms.

\section{Toward a Situative Synthesis of Practices}

Both the behaviorist skill-oriented and cognitive understanding-oriented perspectives have informed the development of educational practices significantly, but they are often portrayed, in research literature and the popular press, as diametrical opposites, where learning according to one view precludes learning according to the other. We argue here that important strengths and values of behaviorist and cognitive practices can be included in practices on the basis of the situative principles of valuing students' learning to participate in inquiry and sensemaking. Situative principles can provide a useful framework for evaluating the contributions of behaviorist and cognitive practices in a larger context. We also propose that educational principles formulated in the situative theoretical framework of the section entitled Framing Assumptions of Theories (beginning on p. 5) can provide a synthesis of behaviorist and cognitive educational principles, ensuring a more coherent basis for designing cur- 
riculum, learning environments, and teaching practices than we have had up to now.

\section{The Behaviorist Perspective}

A key assumption of behaviorist educational practice is that complex skills are learned by acquiring simpler components followed by combinations of these into more complex behavioral abilities. Following this assumption, many curriculum topics have been organized in sequences of behavioral objectives, on the basis of task analyses that decompose complicated behaviors into simpler components. Lessons and tests are organized according to these analyses, with lesson sequences proceeding from simpler to more complex tasks, so that students can learn the simpler components before having to try to acquire more complex components that have those as constituents (Gagné, 1968). Behavioral objectives of instruction can provide clear statements about what students should learn to do and definitive tests of whether they have learned to do those things (e.g., Bloom, 1976), and computational technologies can be designed to provide individualized instruction (e.g., Skinner, 1958; Suppes \& Morningstar, 1972). Teaching practices that rest on behaviorist assumptions include formulating detailed lesson plans, providing students with clear behavioral goals for their learning, and managing classroom activities so that material is presented and practiced efficiently (Brophy \& Good, 1986). Teachers also work to reinforce students' correct behavior by providing approving feedback and to provide incentives that engage students in the activities of learning.

In the situative perspective, skills are understood as aspects of a person's participation in social practicesmetaphorically, as tools that people use to participate successfully. This includes appreciation of the many ways that people can participate in a community's activities with different patterns of behavior. In the social practice of traditional didactic instruction, the display of skill is often treated as the most important form of social participation, and skills are often divorced from their connections to activities in communities outside the classroom. The situative perspective can inform the design of curricula and learning environments in which skills also have functions that go beyond passing tests. For example, in projects that involve complex quantitative relations, individuals who are fluent in computation can make particularly useful contributions. In such situations, it is clear that technical skills have value, but it is also clear that technical skills are not the only basis for making valuable contributions.

The situative perspective also provides a different basis than behaviorism for considering the role of technology in skill acquisition. For example, there is a current debate about whether students need to learn the procedures of paper-and-pencil computation in mathematics, because most of those operations are increasingly performed with electronic calculators. Viewed situatively, behavioral skills always involve participation in systems that include technological resources. Mathematical com- putation with a pencil and a sheet of paper uses a resource that provides a stable record of partial results. In mathematical computation with a simple calculator, the technological resource provides results of elementary operations. With a more complex calculator or a computer, values of algebraic expressions can be provided. Recognizing that processes of reasoning and problem solving are always distributed between agents and the available resources, the discussion need not be framed as the simple question of whether to use calculators or computers at a given stage of students' mathematics education. A more productive discussion could consider progressions of skill that use increasingly complex technological resources and ways in which uses of technologies are included in other practices of reasoning and problem solving, including understanding of quantitative relations and mathematical concepts.

\section{The Cognitive Perspective}

The cognitive perspective focuses on the informational contents of students' minds, rather than on their performance of behaviors. Instead of emphasizing the construction of behavioral skills, cognitive educational practices emphasize the construction of cognitive representations and procedures, including operational structures, schemata, propositional networks, strategies, and conceptual structures that support understanding and reasoning. Three general lines of educational design that are based on this perspective can be distinguished, involving cognitive development, conceptual structures of subject-matter disciplines, and strategic information processing.

Piaget's seminal investigations into cognitive development supported his well-known theory in which children advance by developing general structures of operational reasoning. More recent research studies have examined children's understanding in substantive domains such as biology, physics, and mathematics (e.g., Gelman, 1990; Hirschfeld \& Gelman, 1994), as well as the complexity of operations that children can handle (Case, 1985). These studies have been used in the design of curricula that take into account trajectories of children's conceptual understanding (e.g., Resnick, Bill, Lesgold, \& Leer, 1991; K. J. Roth, 1986; C. Smith, Snir, \& Grosslight, 1992; White, 1993; Wiser \& Kipman, 1988).

Another version of the cognitive perspective has emphasized the conceptual structures of subject-matter disciplines. This includes curriculum design and development in the $1960 \mathrm{~s}$, which was carried out mainly by experts in the subject-matter domains. Subsequently, researchers have identified ways in which students' understanding agrees with or departs from the accepted understandings of disciplinary professionals, especially in science and mathematics. Text materials and class discussions can bring out and address understandings that students have already. This can facilitate students' learning by extending their valid intuitions and by modifying their conceptions that are misaligned with the desired understanding (e.g., Carpenter, Fennema, Peterson, 
Chiang, \& Loef, 1989; diSessa \& Minstrell, in press; Gardner et al., 1990).

The third version of the cognitive perspective involves curriculum, technology, and teaching that are informed by cognitive-science research on information processing. This includes materials and teaching methods for strengthening general learning strategies (Halpern, 1992; Segal, Chipman, \& Glaser, 1985) and specific techniques such as generating explanations for the steps of example problems (Bielaczyc, Pirolli, \& Brown, 1995; Chi, deLeeuw, Chiu, \& LaVancher, 1994). Information-processing models of instructional tasks have been constructed and used as the basis of computer-based tutoring systems that include conceptual and strategic aspects of problem solving and reasoning (e.g., Anderson, Boyle, Corbett, \& Lewis, 1990). Exploratory computational learning environments also have been developed in which students can generate hypotheses and conjectures and gain understanding of the concepts and principles of subject-matter domains through exploratory interactions with representations such as diagrams and dynamic displays of processes (e.g., Reiner et al., 1995; Schwartz, Yarushalmy, \& Wilson, 1993; Spoehr, 1994).

At a general level, the situative perspective subsumes the cognitive perspective by viewing conceptual understanding, like behavioral skill, as an aspect of participation in social practice. This is especially salient in practices where students are engaged with teachers in active inquiry into the meanings and significance of concepts and principles of the subject-matter domain. In these practices, students' understandings - in their activities of formulating and evaluating questions, alternative meanings of concepts, and explanations - contribute to the class's progress in achieving shared understanding, rather than simply displaying the understandings they have constructed in their interactions with textbooks, teachers, and computers.

An issue in the cognitive view of instruction involves the role of students' intuitive understandings of concepts that often seem to differ from the concepts that are recognized in subject-matter disciplines, especially in science and mathematics. A substantial body of research has treated students' intuitive understandings as misconceptions, and educational practices have developed in which teachers confront their students with evidence that contradicts their beliefs. An alternative, presented recently by J. P. Smith, diSessa, and Roschelle (1993-1994), holds that students' understandings are typically collections of intuitive schemata that are valid in many circumstances but that can be applied in ways that lead to incorrect expectations. The situative perspective provides a way to frame the discussion of misconceptions more productively by recognizing that standard meanings of concepts and symbolic forms have evolved in communities of scientific and mathematical practice. The standard meanings and representational forms can then be treated as conventions that have value in supporting reasoning, problem solving, and understanding in significant ways. At the same time, alternative conceptualizations can be treated as valuable as well, especially in providing bases for understanding the space of alternatives in which standard conceptualizations constitute one of the alternatives with special advantages (e.g., Hall \& Rubin, in press; Lampert, 1990a; Moses et al., 1989).

\section{A Pofential Synthesis}

In the Framing Assumptions of Theories section (beginning on p. 5), we discussed ways in which the situative perspective can synthesize behaviorist and cognitive theoretical perspectives. Here we present our view that such a theoretical synthesis can provide a framework of coherent principles to inform educational practices.

At one level, there is a straightforward practical synthesis. An issue that often appears as a fundamental conflict between behaviorist and cognitive views can be redefined in the situative perspective. There often is a conflict between the behaviorist emphasis on learning to do things and the cognitive emphasis on learning with understanding, that is, between allocating resources for students' learning of basic skills versus their learning the conceptual structures of a discipline. In the situative formulation of learning to participate in practices, this conflict is no longer fundamental. This is because the main things that we hope students can learn to do are activities in which technical skills support individual contributions and in which conceptual understandings are both used and constructed. Of course, there are still conflicts in the allocation of limited time for developing different aspects of students' participation in practices. But in the situative perspective, both learning to participate in the discourse of conceptual meanings and learning basic routines of symbol manipulation can both be seen as significant assets for student participation, rather than being orthogonal objectives.

Educational practices that rest on behaviorist and cognitive views can be understood as components of the educational practices that the situative perspective supports. Facility in the routine skills of reading, of writing, and of symbolic manipulation in mathematics and science can be a valuable part of a person's contributions to significant practices of inquiry and sense-making, as can knowledge of extensive information and of standard meanings of terms and concepts. Conceptual growth is an important aspect of a person's participation in substantive discourse both within the conceptual domains of subjectmatter disciplines and in other domains where the disciplines" concepts and principles are useful. We need to organize learning environments and activities that include opportunities for acquiring basic skills, knowledge, and conceptual understanding, not as isolated dimensions of intellectual activity, but as contributions to students' development of strong identities as individual learners and as more effective participants in the meaningful social practices of their learning communities in school and elsewhere in their lives.

\section{An Example: Teaching Mathematics of Proportion}

To make these ideas more concrete with an example, we consider curriculum materials and teaching ratio, propor- 
tion, and scale, which are topics of elementary and middle school mathematics. We discuss presentation of these topics from the points of view of a mainly skill-oriented behaviorist perspective, a mainly concept-oriented cognitive perspective, and a mainly practice-oriented situative perspective.

\section{The Behoviorist Perspective}

In the behaviorist perspective, learning the mathematics of ratio and proportion involves learning to recognize and represent proportional relations and to solve problems about proportions that require numerical multiplication and division. As an example, we take a textbook series by Payne et al. (1985a, 1985b), which included significant material to support students' understanding of operations along with computational exercises. The sixthgrade text (Payne et al., 1985a) has seven lessons on ratio and proportion, each of which explains a concept with an example and gives a page of numerical exercises and word problems. The lessons follow a progression of behavioral objectives, moving from simpler to more complex versions of the mathematical relation and procedures for operating on numerical and quantitative symbols.

1. An introduction distinguishes relations between part-to-part and part-to-total comparisons, which are specified and represented in examples and exercises.

2. A lesson on equal ratios prescnts constants of proportionality represented with tables of values of two variables and gives exercises to fill in missing values in such tables and to identify which of four ratios was unequal to the others in the set.

3. A procedure for finding equal ratios is presented and practiced, involving finding and applying a common multiplier to find the unknown term.

4. A lesson on simplifying ratios presents and uses the operation of dividing the numerator and denominator of a ratio expression by the same number.

5. A lesson defines a proportion as an equation in which two ratios are equated, with examples of mixing different colors of paint.

6. A lesson shows, in an example, that equal ratios have equal cross products, and gives exercises to be solved using cross products to decide whether given ratios are equal.

7. A lesson on problem solving using proportions presents further exercises.

A unit on measurement in the eighth-grade text (Payne et al., 1985b) presents lessons involving representations of quantities.

1. Metric units of length are introduced, and exercises are given involving measuring the lengths of some line segments.

2. Multiplication and division by powers of 10 by moving the decimal point are presented and practiced.

3. Conversion of units of length in the metric system is presented and practiced.

4. Estimations of lengths using sizes of a fingertip, a handspan, and a pace are discussed and practiced.

5. Metric units of weight, volume, and tempcrature are presented and used in exercises of converting units.

7. Precision of measurement is discussed, and numerical exercises involving significant digits are given.
8. Scientific notation is presented and practiced.

9. Problems involving clapsed time and clock time in travel across time zones are illustrated and given as exercises.

10. Units of length in inches, feet, yards, and miles are presented and used in exercises of converting units.

11. Units of volume in pints, quarts, and gallons, and units of weight in ounces, pounds, and tons, are presented and used in exercises of converting units.

Sequences of lessons like these are effective for providing some students with relatively coherent structures of information and skill. Basic concepts and operations are presented, and it is relatively easy to construct assessments to determine which students have acquired the procedures and terminology that the instruction is designed for them to learn. Successful teaching practices in orderly curriculum sequences like these are well understood. They include having clear and explicit goals, a definite instructional plan for each lesson, and well-established routines for the different functional units within lessons, which include providing clear, informative feedback for sludents (e.g., Brophy \& Good, 1986; Leinhardt \& Greeno, 1986).

\section{The Cognitive Perspective}

Curriculum activities for teaching proportions and rational numbers in the cognitive perspective have been informed by two lines of research and analysis of children's understanding of quantitative and numerical proportions. One, in developmental psychology, originated in Piaget's work and examines children's reasoning in a variety of laboratory tasks involving proportional relations between quantities (e.g., Case, 1985; Siegler, 1976). Another large body of cognitive research and analysis, developed mainly in mathematics education, has examined conceptual structures that are needed to understand and reason about rational numbers, including proportions, ratios, rates, and fractional parts of quantities (Carpenter, Fennema, \& Romberg, 1993).

On the basis of the results of cognitive research on concepts of proportional quantities and rational numbers, mathematics educators advocate curricula that include rich opportunities for reasoning about quantitative information. It is not sufficient, they argue, for students to become adept at manipulating the symbolic expressions that represent fractions, percentages, proportions, ratios, and rates. These need to be related meaningfully to the students' understandings of quantitative relations. For example, Lesh and Lamon (1992/1994) have argued for increased use of model-eliciting problems, which present sets of data that students represent in different systematic ways for purposes of making efficient inferences.

An example of curriculum activitics for teaching rational numbers and proportions to middle school students (Curcio \& Bezuk, 1994), which has been distributed by the NCTM as a resource for teachers who wish to use the principles expressed in the NCTM Curriculum and Evaluation Standards (NCTM, 1989). Curcio and Bezuk's materials begin with six activities that are based on the fraction $1 / 2$, which middle school students already 
understand well. Students' understanding is extended in activities that include diagrams of regions divided into two equal areas in many ways, discussion of one half of several numbers, folding sheets of paper, and exercises with a calculator. The second section, called "Benny's Cakes," provides several activities involving division of rectangular and circular regions into parts that are different fractions of the total areas. The third section provides two investigations, one in terms of recycling trash and the other in terms of bags of M\&M candies, in which students consider percentages, ratios, and proportions extensively. Another section develops concepts of ratio and proportion further in geometric activities, including the concept of spatial symmetry.

Curcio and Bezuk's (1994) curriculum was designed according to principles of cognitive constructivism, and emphasizes conceptual understanding and connection to complex situations more than does the more skill-oriented approach of most textbooks. Successful teaching practices in these more constructivist curricula are challenging for many teachers whose education and experience have been in the more routine- and plan-based practices of skill-oriented curricula (e.g., Cohen, McLaughlin, \& Talbert, 1993; Schifter \& Fosnot, 1993). Constructivist teaching is more improvisational, requiring sensitivity to the understandings that students already have in order to help them build on those understandings. Lesson plans that anticipate orderly progress through a small conceptual territory often are derailed when teachers find that some of their students have not yet come to understand an important aspect of concepts or representations that are needed to move ahead. Teachers often refer to the shift from being a "sage on the stage" to being a "guide on the side," recognizing that the kind of leadership that constructivist teachers provide is less directive and more interactive than it is when instruction is oriented primarily toward acquiring skills, vocabulary, and other routine knowledge.

\section{The Situative Perspective}

As we mentioned earlier, the situative perspective provides a way of analyzing whatever practices of teaching and learning occur. There is not a situated way of teaching and learning about proportions and rates that contrasts with nonsituated ways. All teaching and learning are situated; the question is what their situated character is. At the same time, by focusing attention on the practices of learning, knowing, and reasoning in which students participate, many educators have become committed to developing learning environments in which students learn how to participate in practices of reasoning and understanding that go beyond learning computational procedures or acquiring cognitive structures. We discuss two examples of teaching concepts of proportion and rate, one involving class discussions focused on a specific mathematical concept and the other involving activity of design problem solving in which rates and proportions are involved more implicitly.
The classroom discussions and design activities in these examples provide settings that include conceptual discussions and numerical operations. The processes of conceptual inquiry and design activity do not replace the conceptual emphasis or exercise of computational skill that the cognitive and behaviorist perspectives have emphasized. Rather, they provide activity structures in which those aspects of mathematical knowing are meaningful and functional. Successful practice-oriented teaching is even more challenging than constructivist teaching in the cognitive perspective. In the situative perspective, teachers are leaders in their students' growth as participants in mathematical practices. They are, therefore, sensitive not only to what their students have come to know and understand, but also to how their students are currently able to participate in inquiry, discourse, and reasoning, and how they can help them advance to more successful participation. Teachers and students are collaborators in the construction of their shared understanding of mathematics, with teachers serving as mentors in their students' growth in use of mathematical concepts, methods, and values in their reasoning and judgment.

Participation in mathematical inquiry. Lampert (e.g., 1990a, 1990b) has developed innovative practice-oriented teaching methods and examined the processes of her teaching for several years. In a recent study, Hall and Rubin (in press) analyzed videotaped records of several segments of class activity that illustrate Lampert's practice-oriented approach to teaching about distance, time, and speed of motion. They analyzed several incidents in the development and use of a kind of representation that they called a journey line, which represents two extensive quantities - time and distance-by marking units along the line that are labeled with distances above the line and times below the line.

Much of the activity in Lampert's class involved work by groups of four or five students on challenging problems that they discussed with each other. Each student kept a journal in which he or she recorded problem solutions and explanations. Hall and Rubin (in press) distinguished between private activity in which a student worked on solving a problem and reporting the work in her or his journal, local activity involving small conversations within a group or between two or three individuals, and public activity of presentations and discussions involving the whole class. They identified several interactions in which the representational form of a journey line played a role. Their analyses showed ways in which this form functioned as a resource in the class's practices of problem solving and mutual sense-making.

The journey line was constructed by a student, Karim, who was asked by Lampert to explain to another student, Ellie, why one of the problems should be solved using multiplication. Later, Lampert had Karim present the representation and explanation to the class, and Ellie contributed to the explanation of the method on the basis of the representation. In another series of incidents involving private journal work, local conversations, and public discussions, the journey line was used in under- 
standing a problem involving conversion of units of time (hours and minutes) and fractional units of distance in which some students improved their understanding of the problem, which Lampert's students often marked by the phrase "I revised my thinking."

Lampert's teaching, and Hall and Rubin's (in press) analyses of it, highlight several aspects of learning and teaching that are important in the situative perspective. One of these is the role of representational forms, which are used in the class as resources for collaborative sensemaking and reasoning. Another is the variety of ways in which students participate in the practices of mathematical reasoning and discourse. Students in Lampert's classes, and others that are organized similarly, participate as explainers as well as explainees. The construction of explanations is understood as a major focus of class activity.

Participation in projects that use mathematics. Our second example is activity that occurs in the MMAP Project. MMAP was designed to provide middle school students with affordances for participation in reasoning and understanding with mathematics. That is, mathematical reasoning and learning occur primarily, although not exclusively, as a resource in reasoning and understanding in domains other than mathematics. The curriculum materials set up activities for learning mathematics through design activity in four domains: architecture, population biology, cryptography, and cartography. Students' design activities are supported by computer-software tools that are analogous to computer-aided design and modeling tools used by professionals who use mathematics in their work. For example, a curriculum that uses the architecture program has students consider the requirements for living and working space of a research team that will spend two years in Antarctica. (Recall the example that we discussed in the section entitled An Example, beginning on p. 12.) A curriculum that uses the populationbiology modeling program has students consider whether the government of Alaska should institute a policy of controlling the size of wolf populations on public lands to allow growth of caribou populations.

Quantitative reasoning involving proportions, ratios, and rates is essential in the students' design work in these environments, as it is in the activities of many everyday craft and commercial practices (Lave, 1988; Nunes, Schliemann, \& Carraher, 1993; Saxe, 1990). For example, in designing buildings, students construct floor plans on a grid of dots. One of the parameters of the software is a scale factor - the physical length corresponding to each space in the grid. Students reason extensively about the dimensions of the buildings and rooms that they design, corresponding to the lengths of lines in their floor plans. The computer program calculates the cost of constructing the building they have designed, and can display component costs for items such as exterior walls, windows, doors, and partition walls. The students set parameters corresponding to the amount of insulation in their walls, windows, and roofs, which result in increases or decreases in construction cost that they can reason about in terms of unit costs for walls and other components that the software can display. The software also computes the cost of heating the building, using assumptions about average outdoor and indoor temperature that the students enter, and students can investigate the trade-off between construction costs and heating costs associated with increases or decreases in the amount of insulation, as in the example that we included in the section entitled An Example (beginning on p. 12). Design problems can include constraints of the space that the building can occupy and costs projected over several years of use. For example, the building may have to fit in a space with specified length and width, and designs developed by different groups can be compared in terms of their total costs (construction plus heating) over a specified number of years of use.

In the activities of biological modeling, students construct models of population change to address policy issues, such as whether hunting wolves or caribou should be allowed on public lands in Alaska. The program provides an interface in which students define quantities such as annual birth rates and the death rates caused by different factors such as sickness or predation. The students define functions in which changes in these quantities depend on each other, for example, deaths that are due to predation depend on the size of the predator population. The software allows these parameters to be entered in various forms, so that students can experience the difference between constant rates and rates that are proportional to other quantities. When parameters of a model have been entered, the students can run their model and see projected sizes of populations over several years, which can be displayed in tabular or graphical form.

The mathematical reasoning that students achieve in these activities is often quite sophisticated, but it can be quite implicit in their consideration of design features. Teachers have said about these materials that their main effort is uncovering the mathematics that is in students reasoning, which contrasts with their usual concern of covering the required agenda of mathematical topics. To support teachers' efforts to make mathematical concepts and methods explicit, MMAP curricula include materials called "math activities," which can be done in a lesson or two, and "extensions" and "investigations," which can be used for a week or two. In these explicitly mathematical activities, concepts and methods are related to the issues that arise in the design projects, so their meanings are anchored in activities that are not primarily mathematical (cf. Cognition and Technology Group at Vanderbilt, 1990). For example, the curriculum in which students design living and working space for a research team in Antarctica includes math activities in units on measuring length, powers of 10 , scale legends, comparing temperatures on the Fahrenheit and Celsius scales, scale diagrams of classroom objects, area and perimeter, and relationships between area, perimeter, and heating costs. All of these activities present problems in proportional reasoning that are anchored in the building design activities. Math activities included in a curriculum of modeling 
biological populations include scientific notation, birth rates expressed as constants or percentages, linear versus exponential growth and decay, and examination of yearto-year changes in populations as functions of the various parameters of models. Math extensions that relate to these curricula include a one- to two-week unit on proportions involving scale drawings and equivalent fractions and another unit on rational numbers.

\section{CONDUCTING RESEARCH}

In the first two sections, we have argued that the situative perspective can provide a synthesis that subsumes strengths and values of behaviorism and cognitivity. In this section, we discuss a way of conducting research, related to the situative perspective, which also involves a kind of unification. This approach to research brings together activities traditionally considered as basic and applied research, which we refer to as theory-oriented and instrumental functions of research activities. These terms focus on different communities in which problems of research and development are formulated and solutions are proposed, evaluated, and accepted as contributions. Theory-oriented research is organized primarily by questions and problems of developing coherent concepts and explanations in a domain. Instrumental research in education is organized primarily by questions and problems of improving learning environments, including educational materials and teaching methods.

The approach that is emerging, in which instrumental and theory-oriented functions are partially combined, has been called design experiments (A. L. Brown, 1992; Collins, 1992), pioneering research (J. S. Brown, 1991), and interactive research and design (Stucky, 1996). Projects that take this approach include significant efforts to change educational practices, generally with some innovative materials as well as a reorganization of the activities of teaching and learning. They also include significant efforts to understand processes of learning and teaching in the situations where the new materials and practices are being used.

We want to make two points about interactive research and design. First, interactive research and design can be an activity setting in which participants cross the boundaries of professional work that usually separate different communities. We argue that the traditional separation of activities between research, developing materials, and strengthening practices is not the only way to support the advancement of science and educational practice. Instead, we propose that the main distinctions of research and practice involve the communities of accountability in which researchers, developers, and practitioners formulate problems and propose, debate, and evaluate their solutions. In spite of the relative separation of these communities of accountability, there can be close collaboration among researchers, developers, and practitioners in the design of material resources, the evaluation and improvement of these resources and their uses, and the production of information for research.
Our second point about interactive research and design is a possibility that the results of theory-oriented research may become more integrally related to efforts to strengthen practices. Changes in practice depend on changes in underlying assumptions that often are tacit but, nonetheless, function powerfully in organizing and maintaining practices. Research can include efforts to understand the tacit assumptions of practices and to collaborate with practitioners who want to change their practices in directions that can be supported by a better understanding of assumptions of both their present and their desired practices. Results of this kind of research articulate the organizing principles of practical activity, and these principles can become the hypotheses and explanatory principles of our science.

\section{Syncretizing Activities of Research, Development, and Practice}

Traditionally, it has been assumed that basic research, applied research, development, and practice are separate activities, linked only through their products. It has been assumed that basic research produces knowledge that is used in the activities of applied research, applied research produces technologies and prototypes that are used in development, development produces products that can be used in practice, and practitioners use those products. Of course, a certain amount of overlap and feedback between the stages has been recognized, but this has been acknowledged more in lip service than in actual attention. In some cases, this pipeline model of research, development, and practice has corresponded approximately to reality. Examples in education include use of behavioral principles in developing technologies of task analysis (e.g., Gagné, 1968), and use of that technology in constructing behavioral objectives for instruction, assessment, and recommendations to teachers (e.g., Brophy \& Good, 1986) and technologies of individualized instruction (e.g., Skinner, 1958; Suppes \& Morningstar, 1972). More recently, cognitive principles with their origins in laboratory studies have been used in developing methods of instruction that focus on students' problem-solving strategies and conceptual understanding (e.g., Anderson, Boyle, \& Reiser, 1985; Carpenter et al., 1989; McGilly, 1994). These examples of correspondence to the pipeline model may be an artifact of the way we have organized our activities. After all, there are communities in which people conduct basic research and are quite inattentive to results of applied research, development, and practice. There are communities in which people conduct applied research, communities that develop products, and communities of practitioners. All of these communities typically organize their work in ways that are at least partially shaped by the belief that research, development, and practice are related as they are in the pipeline model.

In contrast to research that views contexts of application as issues for the future, the approach that we call interactive research and design takes a different starting point. Instead of originating its inquiry in laboratory studies, it initially focuses on activities in a domain of prac- 
tice. The goals of this research include coming to understand principles that organize that practice, which is a traditional goal of ethnography. Research goals can also include coming to understand cognitive contents and behavioral skills involved in processes of participation, thereby including the cognitive and behaviorist perspectives in the research agenda. At the same time, there is another goal of obtaining information and understanding that can support changes in resources and activities that would strengthen the practice.

Projects of interactive research and design in education focus on practices of learning and understanding, including changes in practices and changes in the social organization of learning environments. Researchers, developers, and teachers have organized materials and instructional arrangements to demonstrate and study learning in activity structures where students participate in formulating and evaluating questions and problems, as well as solutions, conclusions, explanations, arguments, and examples. Studies of this kind include Lampert's studies and the MMAP Project involving mathematics teaching and learning that we discussed in the section entitled The Situative Perspective (beginning on p. 19), as well as A. L. Brown and Campione's Community of Learners Project (A. L. Brown, 1992; A. L. Brown \& Campione, 1994), the Fifth Dimension Project in San Diego, CA (Laboratory of Comparative Human Cognition, 1982), the Jasper Project at Vanderbilt University (Cognition and Technology Group at Vanderbilt, 1994), the Computer Supported Intentional Learning Environment (CSILE) Project in Toronto, Ontario, Canada (Scardamalia et al., 1994), the Connections School Project in Cambridge, MA (Collins et al., 1991), the Quantitative Understanding: Aligmenting Student Achievement and Reasoning (QUASAR) Project in Pittsburgh, PA (Silver \& Stein, 1996), and the Problem-Based Mathematics Project at Purdue University and Vanderbilt University (Cobb et al., 1991).

Conducting interactive research and design requires a different kind of collaboration with practitioners than researchers have had traditionally. In traditional relationships, researchers mainly have been outside observers and analysts, whereas teachers have been subjects of the research, or research has been conducted away from the domain of practice and researchers have formulated their recommendations as prescriptions that teachers should follow. In interactive research and design, practitioners are the principal designers of change in their practices and, to a significant extent, are coinvestigators in the research that has their practice as its main topic.

In MMAP, for example, researchers, curriculum developers, and teachers have worked together from the early stages of the project, designing the software and curriculum materials, analyzing and evaluating the teaching practices and learning that occur when the materials are used, and designing changes in the materials and supplementary materials for use by other teachers. In our work, there is a core of activity that primarily involves design, evaluation, and redesign of materials and prac- tices in which researchers, developers, and teachers all participate.

The integration of research, development, and practice in MMAP, and in other similarly organized projects, is not a complete synthesis; that is, these different functions of our activity are not merged or subsumed under any one of them. Rather, the combination is syncretic. Our functions remain separate in that we are primarily accountable to different communities for the success of our respective aspects of the activity. Teachers and developers treat the outcomes as instrumental research, contributing to the improvement of their practices and products. Teachers have their main responsibility in their work with students and to their communities of professional colleagues, and their uses of the resources developed in the project are determined by the judgments they make about their students' learning. Developers have their main responsibility in the construction of software and curriculum materials that can be distributed and used broadly. Researchers treat the outcomes of the shared activities as theory-oriented research. Researchers have their main responsibility in the advancement of knowledge and understanding of principles of knowing and learning, which are informed by analyses of social interactions in classrooms and of uses of the resources developed in the project.

These differences, however, do not preclude significant collaboration in the design and evaluation activities of the project. Each member of the group takes on some of the responsibility for all of the aspects of the work, and, indeed, several members of the team work as both a teacher and a developer, as both a developer and a researcher, or as both a teacher and a researcher. The design of materials, evolution of teaching practices, successful learning by students, and articulation of concepts and principles consistent with the experiences and observations of learning activity, all become part of each member's concerns.

The novel aspect of our work, for us, has been the extent to which, in satisfying our different responsibilities, we have been supported by the design, evaluation, and redesign work in which we all collaborate. This contrasts with a more common pattern in which there is a group of researchers who do research, a group of developers who do development, and a group of teachers who do teaching, and the groups try to talk with each other about their constraints and results. The pattern of interaction that has evolved in our work is more complicated, and we have found it extraordinarily productive.

Conducting interactive research and design does not require that the participants must adopt a situative perspective on their practices and research, but this kind of project fits particularly well with the situative perspective as we have been discussing it. In the situative perspective, we expect to discover general principles of activity by carefully examining and analyzing the activities of people engaged in socially organized work, and the kind of socially organized work that occurs when people are trying 
to change their practices can be particularly productive for that goal of research.

Some critics (e.g., Vera \& Simon, 1993a) have written that the situative view implies that understanding of fundamental principles of behavior cannot be advanced by research in settings other than naturally occurring activity. We believe that this is not an implication of the situative view. Instead, the situative view implies that behavior in all research settings should be analyzed as interactions, for example, by considering the activities of participants in laboratory experiments as interactions with the experimenter and the material and informational systems that are used. Observed behavior can be explained in terms of the participants' attunements to constraints and affordances of the experimental situation, and claims for generality of the findings should be supported by arguments that the attunements in these circumstances are informative regarding fundamental principles of activity. The special conditions of experiments are an important resource for investigating processes of thinking, perceiving, remembering, and communicating, but those special conditions should be taken into account in the interpretations of the findings.

\section{A Possible Synthesis of Principles}

We have described an approach to research in which a core of activities is conducted by a collaborating group of researchers, developers, and practitioners. The goal of research in this approach is to understand and articulate principles that organize the practitioners' activity, from their perspective, which correspond to tacit assumptions that underlie their practices. This leaves open the question of whether the fundamental principles that are understood by practitioners in the organization of their activity are the same as the fundamental principles that are needed for a systematic theory of activity. This is a profound epistemological question that will be addressed in research and practical work for some time. Taking the positive view is, it seems to us, the fundamental commitment of ethnography, that is, the commitment that a community's activity can be understood best by achieving understanding from that community's perspective.

Research about systems of activity involves coming to understand the principles that organize the activities of communities of practice. Changes in the practices of communities generally involve changes in the principles that are assumed, at least tacitly, in the commitments of the participants. In this view, efforts to change practice need to be informed by an understanding of the assumptions of the practices that the community wants to change from, as well as an understanding of the changes in assumptions that would support the kind of practice that the community wants to change to, involving reflective activity by the practitioners (cf. A. L. Brown, 1994; J. S. Brown, 1991; Schön, 1983). This suggests that understanding the organizing principles of activity may be fundamental to both researchers and practitioners. The analytical work of research and the reflective work of changing practice may arrive at a single set of results - a set of representations that explicate the tacit assumptions of practice. On the other hand, it might turn out that principles that are crucial in organizing the activities of a community function at a level that is different from the level that is needed for a systematic theory, perhaps because the level of consistency needed for a theoretical account is unnecessary for effective practice, or is even counterproductive.

Although the ultimate question of consistency between goals and results of theory-oriented and instrumental research is open, it seems clear to us that progress toward understanding first principles and tacit assumptions of practices is a fundamental goal of theory-oriented research. In the situative perspective, the focus of theoretical principles is at the level of interactions among people and between people and their environments. This does not remove the distinction between goals of theory-oriented and instrumental research, but it at least locates them at the same level of aggregation and complexity. For fundamental knowledge in the situative perspective to be used in applications, its orientation needs to go beyond concerns with relations of consistency and implication among the general meanings of theoretical concepts and principles. It needs also to include relations among functions of activity in its settings and relations between resources or impediments and the activities that they support or hinder. By developing our science in a different relation to practice, we may evolve an epistemological shift away from asking primarily whether our propositions are true to a greater emphasis on whether our principles are useful as assumptions of practice. That, too, would be consistent with the views of American pragmatists such as Dewey (e.g., 1916/1966).

\section{CONCLUSIONS}

We have considered aspects of three interrelated issues: the framing assumptions of theories, different ways of organizing educational practice, and the conduct of educational research. Our goal has been to show how these issucs are influenced by adopting what we call the situative perspective, that is, a perspective that focuses attention on systems in which people interact with each other and with material, informational, and conceptual resources in their environments.

We have presented our view that this perspective provides a basis for a synthesis of framing assumptions of psychological theory and principles of educational practice that can subsume important aspects of cognitive and behaviorist perspectives. We also have described an approach to research - interactive research and designthat is not limited to the situative perspective, but fits well with its conceptual commitments and provides a syncretic combination of research, development, and practice. Our proposal about theoretical frameworks and principles of practice is an alternative to the view that research on human activity and the practice of education move along separate tracks. In our view, we should try to integrate the findings, concepts, and explanations of research and practice into as coherent an account as we 
can achieve, and we argue that the situative perspective provides a promising framework for doing this. Whether this succeeds will depend, of course, on the progress of future research, including the kind of interactive research and design that we have described, along with the other approaches that our field has available.

\section{REFERENCES}

Abraham, R. H., \& Shaw, C. D. (1992). Dynamirs: The geometry of behavior. Redwood City, CA: Addison-Wesley.

Anderson, J. R., Boyle, C. F., Corbett, A. T., \& Lewis, M. W. (1990). Cognitive modeling and intelligent tutoring. Artificial Intelligence, $42,7-50$.

Anderson, J. R., Boyle, C. F., \& Reiser, B. J. (1985). Intelligent tutoring systems. Science, 228, 456-462.

Anderson, J. R., Reder, L., \& Simon, H. A. (1996). Situated learning and education. Educational Researcher, 25(4), 5-11.

Anderson, J. R., Reder, L., \& Simon, H. A. (1997). Situative and cognitive perspectives: Form versus substance. Educational Researcher, $26(1), 18-21$.

Ball, D. L. (1993). Halves, pieces, and twoths: Constructing representational contexts in teaching fractions. In T. P. Carpenter, E. Fennema, \& T. A. Romberg (Eds.), Rational numbers: An integration of research (pp. 157-195). Hillsdale, NJ: Erlbaum.

Bartlett, F. C. (1932). Remembering: A study in experimental and social psychology. New York: Macmillan.

Barwise, J. (1993). Constraints, channels, and the flow of information. In P. Aczel, D. Israel, Y. Katagiri, \& S. Peters (Eds.), Situation theory and its applications (Vol. 3, pp. 3-29). Stanford, CA: Stanford University, Center for the Study of Language and Information.

Barwise, J., \& Perry, J. (1983). Situations and attitudes. Cambridge, MA: MIT Press.

Bateson, G. (1972). Steps toward an ecology of mind. New York: Ballantine Books.

Belenky, M. F., Bond, L. A., \& Weinstock, J. S. (1997). A tradition that has no name: Nurturing the development of people, families, and communities. New York: Basic Books.

Belenky, M. F., Clinchy, B. M., Goldberger, N. R., \& Tarule, J. M. (1986). Women's ways of knowing. New York: Basic Books.

Bielaczyc, K., Pirolli, P. L., \& Brown, A. L. (1995). Training in selfexplanation and self-regulation strategies for learning computer programming. Cognition and Instruction, 13, 161-188.

Bloom, B. S. (1976). Human characteristics and school learning. New York: McGraw-Hill.

Brophy, J. E., \& Good, T. L. (1986). Teacher behavior and student achievement. In M. C. Wittrock (Ed.), Handbook of research on teaching (3rd ed., pp. 328-375). New York: Macmillan.

Brown, A. L. (1992). Design experiments: Theoretical and methodological challenges in creating complex interventions in classroom settings. Journal of the Learning Sciences, 2, 141-178.

Brown, A. L. (1994). Advancing learning. Educational Researcher, 23(8), 4-12.

Brown, A. L., \& Campione, J. C. (1994). Guided discovery in a community of learners. In K. McGilly (Ed.), Classroom lessons: Integrating cognitive theory and classroom practice (pp. 229-270). Cambridge, MA: MIT Press/Bradford.

Brown, J. S. (1991, January-February). Research that reinvents the corporation. Harvard Business Review, pp. 102-111.

Brown, L. M., \& Gilligan, C. (1992). Meeting at the crossroads. New York: Ballantine Books.

Carpenter, T. P., Fennema, E., Peterson, P. L., Chiang, C.-P., \& Loef, M. (1989). Using knowledge of children's mathematical thinking in classroom teaching: An experimental study. American Educational Research Journal, 26, 499-531.

Carpenter, T. P., Fennema, E., \& Romberg, T. A. (Eds.). (1993). Rational numbers: An integration of research. Hillsdale, NJ: Erlbaum.

Case, R. (1985). Intellectual development: Birth to adulthood. Orlando, FL: Acadernic Press.

Chi, M. T. H., deLeeuw, N., Chiu, M.-H., \& LaVancher, C. (1994).
Eliciting self-explanations improves understanding. Cognitive Science, 18, 439-478.

Clancey, W. J. (1997). Situated cognition. Cambridge, England: Cambridge University Press.

Clark, H. H. (1996). Using language. Cambridge, England: Cambridge University Press.

Clark, H. H., \& Schaefer, E. F. (1989). Contributing to discourse. Cog. nitive Science, 13, 259-294.

Clark, H., H., \& Wilkes-Gibbs, D. (1986). Referring as a collaborative process. Cognition, 22, 1-39.

Cobb, P., Wood, T., Yackel, E., Nicholls, J., Wheatley, G., Trigatti, B., \& Perlwitz, M. (1991). Assessment of a problem-centered second-grade mathematics project. Journal for Research in Mathematics Education, 22, 3-29.

Cognition and Technology Group at Vanderbilt. (1990). Anchored instruction and its relationship to situated cognition. Educational Researcher; $19(5), 2-10$.

Cognition and Technology Group at Vanderbilt. (1994). From visual word problems to learning communities: Changing conceptions of cognitive research. In K. McGilly (Ed.), Classroom lessons: Integrating cognitive theory and classroom practice (pp. 157-200). Cambridge, MA: MIT Press/Bradford.

Cohen, D. K., McLaughlin, M. W., \& Talbert, J. E. (Eds.). (1993). Teaching for understanding: Challenges for policy and practice. San Francisco: Jossey-Bass.

Collins, A. (1992). Toward a design science of education. In E. Scanlon \& T. O'Shea (Eds.), New directions in educational technology (pp. 15-22). Berlin, Germany: Springer.

Collins, A., Hawkins, J., \& Carver, S. M. (1991). A cognitive apprenticeship for disadvantaged students. In B. Means, C. Chelemer, \& M. S. Knapp (Eds.), Teaching advanced skills to at-risk students (pp. 216-243). San Francisco: Jossey-Bass.

Curcio, F. R., \& Bezuk, N. S. (1994). Understanding rational numbers and proportions. Reston, VA: National Council of Teachers of Mathematics.

Devlin, K. (1991). Logic and information. Cambridge, England: Cambridge University Press.

Dewey, J. (1896). The reflex arc concept in psychology. Psychological Review, 3, 357-370.

Dewey, J. (1958). Experience and nature. New York: Dover. (Original work published 1929)

Dewey, J. (1966). Democracy and education. New York: Free Press. (Original work published 1916)

Dewey, J. (1978). How we think. In Jo Ann Boydston (Ed.), J. Dewey, How we think and selected essays, 1910-1911 (pp. 177-356). Carbondale, IL: Southern Illinois University Press. (Original work published 1910)

diSessa, A. A., \& Minstrell, J. (in press). Cultivating conceptual change with benchmark lessons. In J. G. Greeno \& S. V. Goldman (Eds.), Thinking practices in mathematics and science learning. Mahwah, NJ: Erlbaum.

Dweck, C. S., \& Leggett, E. L. (1988). A social-cognitive approach to motivation and personality. Psychological Review, 95, 256-273.

Eckert, P. (1989). Jocks and burnouts. New York: Teachers College Press.

Eckert, P. (1990). Adolescent sacial categories: Information and science learning. In M. Gardner, J. G. Greeno, F. Reif, A. H. Schoenfeld, A. diSessa, \& E. Stage (Eds.), Toward a scientific practice of science education (pp. 203-217). Hillsdale, NJ: Erlbaum.

Fawcett, H. (1938). The nature of proof. New York: Columbia University, Teachers College.

Gagné, R. M. (1968). Learning hierarchies. Educational Psychologist, 6, $1-9$.

Gardner, M., Greeno, J. G., Reif, F., Schoenfeld, A. H., diSessa, A., \& Stage, E. (Eds.). (1990). Toward a scientific practice of science education. Hillsdale, $\mathrm{NJ}$ : Erlbaum.

Gelman, R. (Ed.). (1990). Structural constraints on cognitive development. Cognitive Science, 14, 1-178.

Gibson, E. J. (1988). Exploratory behavior in the development of perceiving, acting, and the acquiring of knowledge. Annual Review of Psychology, 39, 1-41. 
Gibson, J. J. (1986). An ecological approach to visual perception. Hillsdale, NJ: Erlbaum. (Original work published 1979)

Goldman, S. V. (1996). Mediating micro-worlds: Collaboration on high school science activities. In. T. Koschmann (Ed.), Computer support for collaborative work (pp. 45-81). Mahwah, NJ: Erlbaum.

Goldman, S., Moschkovich, J. N., \& the Middle School Mathematics Through Applications Project Team. (1995). Environments for collaborating mathematically. In J. L. Schnase \& E. L. Cunnius (Eds.), Proceedings of $C S C L$ '95: The first international conference on computer support for collaborative leaming (pp. 1-4). Hillsdale, NJ Erlbaum.

Goodwin, C., \& Goodwin, M. H. (1996). Seeing as situated activity: Formulating planes. In Y. Engeström \& D. Middleton (Eds.), Cognition and communication at work (pp. 61-95). Cambridge, England: Cambridge University Press.

Greeno, J. G. (1995). Understanding concepts in activity. In C. A. Weaver, III, S. Mannes, \& C. R. Fletcher (Eds.), Discourse compre hension: Essays in honor of Walter Kintsch (pp. 65-96). Hillsdale, NJ: Erlbaum.

Greeno, J. G. (1997). On claims that answer the wrong questions. Educational Researcher, 25(1), 5-17.

Greeno, J. G., Collins, A., \& Resnick, L. B. (1996). Cognition and learning. In R. Calfee \& D. Berliner (Eds.), Handbook of educational psychology (pp. 15-46). New York: Macmillan Library Reference.

Greeno, J. G., \& Engle, R. A. (1995). Combining analyses of cognitive processes, meanings, and social participation: Understanding symbolic representations. In J. D. Moore \& J. F. Lehman (Eds.), Proceed ings of the 17th annual conference of the Cognitive Science Society (pp. 591-596). Hillsdale, NJ: Erlbaum.

Greeno, J. G., \& Moore, J. L. (1993). Situativity and symbols: Response to Vera and Simon. Cognitive Science, 17, 49-60.

Greeno, J. G., Smith, D. R., \& Moore, J. L. (1993). Transfer of situated learning. In D. K. Detterman \& R. J. Sternberg (Eds.), Transfer on trial: Intelligence, cognition, and instruction (pp. 99-167). Norwood, NJ: Ablex.

Hall, R. P. (1996). Representation as shared practice: Situated cognition and Dewey's cartography of experience. Journal of the Learning Sciences, 5, 211-240.

Hall, R., \& Rubin, A. (in press). . . . there's five little notches in here: Dilemmas in teaching and leaming the conventional structure of rate. In J. G. Greeno \& S. V. Goldman (Eds.), Thinking practices in mathematics and science learning. Mahwah, NJ: Erlbaum.

Halpern, D. F. (Ed.). (1992). Enhancing thinking skills in the sciences and mathematics. Hillsdale, NJ: Erlbaum.

Hatano, G., \& Inagaki, K. (1991). Sharing cognition through collective comprehension activity. In L. B. Resnick, J. M. Levine, \& S. D. Teasley (Eds.), Perspectives on socially shared cognition (pp. 331-348) Washington, DC: American Psychological Association.

Hatfield, G. (1991). Representation in perception and cognition: Connectionist affordances. In W. Ramsey, S. P. Stich, \& D. E. Rumelhart (Eds.), Philosophy and connectionist theory (pp. 163-195). Hillsdale, NJ: Erlbaum.

Healy, C. C. (1993). Creating miracles: A story of student discovery. Berkeley, CA: Key Curriculum Press.

Hirschfeld, L. A., \& Gelman, S. A. (Eds.). (1994). Mapping the mind: Domain specificity in cognition and culture. Cambridge, England Cambridge University Press.

Just, M. A., \& Carpenter, P. A. (1980). A theory of reading: From eye fixations to comprehension. Psychological Review, 87, 329-354.

Kantor, J. R. (1945). Psychology and logic (Vol. 1). Bloomington, IN: Principia.

Kintsch, W., \& van Dijk, T. A. (1978). Toward a model of text comprehension and production. Psychological Review, 85, 363-394.

Laboratory of Comparative Human Cognition. (1982). A model system for the study of learning difficulties. The Quarterly Newsletter of the Laboratory of Comparative Human Cognition, 4, 39-66.

Lampert, M. (1990a). Connecting inventions with conventions. In L. P. Steffe \& T. Wood (Eds.), Transforming children's mathematics education: International perspectives (pp. 253-265). Hillsdale, NJ Erlbaum.

Lampert, M. (1990b). When the problem is not the question and the solution is not the answer: Mathematical knowing and teaching. American Educational Research Journal, 17, 29-64.

Lave, J. (1988). Cognition in practice. Cambridge, England: Cambridge University Press.

Lave, J., \& Wenger, E. (1991). Situated learning: Legitimate peripheral participation. Cambridge, England: Cambridge University Press.

Leinhardt, G., \& Greeno, J. G. (1986). The cognitive skill of teaching. Joumal of Educational Psychology, 78, 75-95.

Lepper, M. R., \& Greene, D. (1979). The hidden costs of reward. Hillsdale, NJ: Erlbaum.

Lesh, R., \& Lamon, S. J. (1994). Assessing authentic mathematical performance. In R. Lesh \& S. J. Lamon (Eds.), Assessment of authentic performance in school mathematics (pp. 17-62). Hillsdale, $\mathrm{NJ}$ : Erlbaum. (Original work published 1992)

Lewin, K. (1936). Principles of topological psychology. New York: McGraw-Hill.

Lewin, K. (1946). Behavior and development as a function of the total situation. In L. Carmichael (Ed.), Manual of child psychology (pp. 791-844). New York: Wiley.

McGilly, K. (Ed.). (1994). Classroom lessons: Integrating cognitive theory and classroom practice. Cambridge, MA: MIT Press/ Bradford.

Mead, G. H. (1934). Mind self, and society from the standpoint of a social behaviorist (C. W. Morris, Ed.). Chicago: University of Chicago Press.

Merleau-Ponty, M. (1962). The phenomenology of perception. New York: Humanities Press. (Original work published 1942)

Miyaki, N. (1986). Constructive interaction and the iterative process of understanding. Cognitive Science, 10, 151-177.

Moses, R. P., Kamii, M., Swap, S. M., \& Howard, J. (1989). The Algebra Project: Organizing in the spirit of Ella. Harvard Educational Review, 59, 423-443.

National Council of Teachers of Mathematics. (1989). Curriculum and evaluation standards for school mathematics. Reston, VA: Author

Newell, A., \& Simon, H. A. (1972). Human problem solving. Englewood Cliffs, NJ: Prentice Hall.

Norman, D. A. (Ed.). (1993). Situated action. Cognitive Science, 17, $1-133$.

Nunes, T., Schliemann, A. D., \& Carraher, D. W. (1993). Street mathematics and school mathematics. Cambridge, England: Cambridge University Press.

Osherson D. N., \& Smith, E. E. (Eds.). (1990). An invitation to cognitive science (Vols. 1-3). Cambridge, MA: MIT Press.

Payne, J. N., Beardsley, L. M., Bunch, B. H., Carter, B. B., Coburn, T. G., Edmonds, G. F., Payne, R. C., Rathmell, E. C., Trafton, P. R., Greeno, J. G., \& Jones, P. S. (1985a). Harper \& Row mathematics (kindergarten-6th grade, 2nd ed.). New York: Harper \& Row.

Payne, J. N., Bunch, B. H., Coburn, T. G., Crawford, R. A., Jr., Edmonds, G. F., Lankford, F. G., Jr., \& Trafton, P. R. (1985b). Harper \& Row mathematics (7th and 8th grades, 2nd ed.). New York: Harper \& Row.

Peirce, C. S. (1955). Logic as semiotic: The theory of signs. In J. Buchler (Ed.), Philosophical writings of Peirce (pp. 98-119). New York: Dover. (Original works published 1897-1910.)

Posner, M. I. (Ed.). (1989). Foundations of cognitive science. Cambridge, MA: MIT Press/Bradford.

Reed, E. S. (1996). Encountering the world: Toward an ecological psychology. New York: Oxford University Press.

Reiner, M., Pea, R. D., \& Shulman, D. J. (1995). Impact of simulatorbased instruction on diagramming in geometrical optics by introductory physics students. Journal of Science Education and Technology, 4, $199-226$.

Reitman, W. R. (1965). Cognition and thought. New York: Wiley.

Resnick, L. B., Bill, V. L., Lesgold, S. B., \& Leer, M. N. (1991). Thinking in arithmetic class. In B. Means, C. Chelemer, \& M. S. Knapp (Eds.), Teaching advanced skills to at-risk students (pp. 27-53). San Francisco: Jossey-Bass.

Rogoff, B., \& Chavajay, P. (1995). What's become of research on the cultural basis of cognitive development? American Psychologist, 50 , $859-877$.

Roth, K. J. (1986). Conceptual-change learning and student processing 
of science texts (Research Series No. 167). East Lansing, MI: Michigan State University, Institute for Research on Teaching.

Roth, W.-M., \& Bowen, G. M. (1993-1994). An investigation of problem framing and solving in a grade 8 open-inquiry science program. Journal of the Learning Sciences, 3, 165-204.

Sacks, H., Schegloff, E. A., \& Jefferson, G. (1974). A simplest systematics for the organization of turn-taking in conversation. Language, $50,696-735$

Saxe, G. (1990). Culture and cognitive development: Studies in mathematical understanding. Hillsdale, NJ: Erlbaum.

Scardamalia, M., Bereiter, C., \& Lamon, M. (1994). The CSILE Project: Trying to bring the classroom into World 3. In K. McGilly (Ed.), Classroom lessons: Integrating cognitive theory and classroom practice (pp. 201-228). Cambridge MA: MIT Press/Bradford.

Schegloff, E. A. (1972). Notes on a conversational practice: Formulating place. In D. Sudnow (Ed.), Studies in social interaction (pp. 75119). New York: Free Press.

Schegloff, E. A. (1991). Conversation analysis and socially shared cognition. In L. B. Resnick, J. M. Levine, \& S. D. Tèasley (Eds.), Perspectives in socially shared cognition (pp. 150-171). Washington, DC: American Psychological Association.

Schifter, D., \& Fosnot, C. T. (1993). Reconstructing mathematics education: Stories of teachers meeting the challenge of reform. New York Teachers College Press.

Schoenfeld, A. H. (1994). Reflections on doing and teaching mathematics. In A. H. Schoenfeld (Ed.), Mathematical thinking and problem solving (pp. 53-70). Hillsdale, NJ: Erlbaum.

Schön, D. (1983). The reflective practitioner: How professionals think in action. New York: Basic Books.

Schwartz, J. L., Yarushalmy, M., \& Wilson, B. (Eds.). (1993). The geometric supposer: What is it a case of? Hillsdale, NJ: Erlbaum.

Segal, J. W., Chipman, S. F., \& Glaser, R. (Eds.). (1985). Thinking and learning skills, Volume 1: Relating instruction to research. Hillsdale, NJ: Erlbaum.

Siegler, R. S. (1976). Three aspects of cognitive development. Cognitive Psychology, 4, 481-520.

Silver, E. A., \& Stein, M. K. (1996). The QUASAR Project: The "revolution of the possible" in mathematics instructional reform in urban middle schools. Urban Education, 30, 476-522.

Simon, H. A. (1973). The structure of ill structured problems. Artificial Intelligence, 4, 181-201.

Simon, H. A. (1978). The sciences of the artificial (2nd ed.). Cambridge, MA: MIT Press.

Skinner, B. F. (1958). Teaching machines. Science, 128, 969-977.
Smith, C., Snir, J., \& Grosslight, L. (1992). Using conceptual models to facilitate conceptual change. Cognition and Instruction, 9, 221 283.

Smith, J. P., III, diSessa, A. A., \& Roschelle, J. (1993-1994). Miscon ceptions reconceived: A constructivist analysis of knowledge in transition. Journal of the Learning Sciences, 3, 115-164.

Spoehr, K. T. (1994). Enhancing the acquisition of conceptual structures through hypermedia. In K. McGilly (Ed.), Classroom lessons: Inte grating cognitive theory and classroom practice (pp. 75-101). Cambridge, MA: MIT Press/Bradtord.

Star, S. L. (1996). Working together: Symbolic interactionism, activity theory, and information systems. In Y. Engeström \& D. Middleton (Eds.), Cognition and communication at work (pp. 296-318). Cambridge, England: Cambridge University Press.

Stucky, S. (1996). Interactive research and design: Bringing ideas to life through a fresh vision of R\&D. In B. Bautista (Ed.), Annual report, 1995-1996. Menlo Park, CA: Institute for Research on Learning.

Suchman, L., \& Trigg, R. (1993). Artificial intelligence as craftwork. In S. Chaiklin \& J. Lave (Eds.), Understanding practice: Perspectives on activity and context (pp. 144-178). Cambridge, England: Cambridge University Press.

Suppes, P., \& Morningstar, M. (1972). Computer-assisted instruction at Stanford, 1966-68. New York: Academic Press.

Thelen, E., \& Smith, L. B. (1994). A dynamic systems approach to the development of cognition and action. Cambridge, MA: MIT Press/ Bradford.

Vallacher, R. R., \& Nowak, A. (Eds.). (1994). Dynamical systems in social psychology. San Diego, CA: Academic Press.

Vera, A., \& Simon, H. A. (1993a). Situated action: A symbolic interpretation. Cognitive Science, 17, 7-42.

Vera, A., \& Simon, H. A. (1993b). Situated action: Reply to reviewers. Cognitive Science, 17, 77-86.

Vygotsky, L. (1987). Thinking and speech. In R. W. Rieber \& A. S. Carton (Eds.), The collected works of L. S. Vygotsky, Volume 1: Problems of general psychology (pp. 37-285). New York: Plenum. (Original work published in Russian, 1934.)

Wenger, E. (in press). Communities of practice: Learning, meanings, and identity. Cambridge, England: Cambridge University Press.

White, B. Y. (1993). ThinkerTools: Causal models, conceptual change, and science education. Cognition and Instruction, 10, 1-100.

Wiser, M., \& Kipman, D. (1988). The differentiation of heat and temperature: An evaluation of the effect of microcomputer models on students' misconceptions (Report No. TR88-20). Cambridge, MA: Harvard University, Educational Technology Center. 